\title{
Metabolic signaling functions of ER-mitochondria contact sites: role in metabolic diseases
}

\author{
Emily Tubbs ${ }^{1}$ and Jennifer Rieusset ${ }^{2}$ \\ 1Department of Clinical Sciences, Lund University Diabetes Centre, Malmö, Sweden \\ 2INSERM UMR-1060, CarMeN Laboratory, Lyon 1 University, INRA U1235, INSA of Lyon, Charles Merieux \\ Lyon-Sud medical Universities, Lyon, France
}

Correspondence should be addressed to J Rieusset Email jennifer.rieusset@univ-lyon1. $\mathrm{fr}$

\begin{abstract}
Beyond the maintenance of cellular homeostasis and the determination of cell fate, ERmitochondria contact sites, defined as mitochondria-associated membranes (MAM), start to emerge as an important signaling hub that integrates nutrient and hormonal stimuli and adapts cellular metabolism. Here, we summarize the established structural and functional features of MAM and mainly focus on the latest breakthroughs highlighting a crucial role of organelle crosstalk in the control of metabolic homeostasis. Lastly, we discuss recent studies that have revealed the importance of MAM in not only metabolic diseases but also in other pathologies with disrupted metabolism, shedding light on potential common molecular mechanisms and leading hopefully to novel treatment strategies.
\end{abstract}

\author{
Key Words \\ - organelle communication \\ - mitochondria-associated \\ membranes \\ - calcium signaling \\ - metabolic homeostasis \\ - insulin resistance \\ - type 2 diabetes mellitus \\ - PP2A
}

\section{Introduction}

Cellular metabolism is closely regulated and compartmentalized within distinct subcellular organelles. Mitochondria and endoplasmicreticulum(ER) play a crucial role in these processes, as their structure and function are dynamically regulated by nutritional and environmental cues, influencing energy metabolism. Particularly, both organelles are nutrient and energy sensors (Mandl et al. 2009, Gao et al. 2014), allowing the adaptation of cellular metabolism according to nutritional status. Moreover, both ER and mitochondria have recently emerged as crucial regulators of the innate immune response to both pathogens and cell stress (Martinon 2012, Lartigue \& Faustin 2013), thus further controlling the metabolic adaptations in function of immune modifications. In this context, the liver is a key organ integrating both nutrient and immune signals, as it is the first organ reached by nutrients and bacterial components of the gut during food intake, highlighting the importance of the gut-liver axis in the adaptation to nutritional environment changes (Chassaing et al. 2014). However, excess of nutrients or intestinal microbiota modifications (i.e. altered microbiota population and/or altered gut permeability) could be a source of pro-inflammatory agonists that could alter hepatic metabolism. Therefore, a precise integration of both metabolic and inflammatory pathways is essential for the adaptations of hepatic metabolism to environment, but more generally for the regulation of whole-body metabolism. In agreement, mitochondrial dysfunction and ER stress have been largely and independently associated with metabolic diseases, such as obesity, type 2 diabetes mellitus (T2DM) (Chang et al. 2015, Rieusset 2015, Salvado et al. 2015, Wang et al. 2015, Hasnain et al. 2016) and non-alcoholic fatty liver diseases (NAFLD) (Begriche et al. 2013, Takaki et al. 2014, Ashraf

Published by Bioscientifica Ltd 
\& Sheikh 2015). Moreover, the strong interplay between the two organelles and immune signaling (Hummasti \& Hotamisligil 2010, Chaudhari et al. 2014) further highlights their involvement in the progression toward metabolic diseases. Therefore, mitochondria and ER play an important role in metabolic homeostasis; yet, the precise mechanisms are still unclear.

An interesting and underestimated point is that both organelles are not independent but rather interconnected intracellular organelles, sharing structural and functional interactions allowing reciprocal regulations. The close contacts between ER and mitochondria, known as mitochondria-associated endoplasmic reticulum membranes (MAM), shelter various proteins with different functions and play a pivotal role in different established functions such as calcium $\left(\mathrm{Ca}^{2+}\right)$ signaling, lipid transport, mitochondrial functions and cell survival (Giorgi et al. $2015 b$ ). However, recent data shed light on additional roles of MAM in nutrient and hormonal signaling, highlighting an emerging role of MAM in the control of metabolic homeostasis. Consequently, it is a close step to suggest that ER-mitochondria miscommunication could have a role in metabolic diseases.

Here, we review the established structural and functional features of ER-mitochondria interactions and discuss the important considerations to take into account when we analyze these domains. Particularly, we will focus on the emerging role of MAM in nutrient and hormonal signaling, highlighting a key role of organelle crosstalk to maintain metabolic homeostasis. Lastly, we will discuss the potential role of ER-mitochondria miscommunication in metabolic diseases.

\section{Structural and functional features of MAM}

To be as clear and complete as possible, we will start this review with an overview of the established components and functions of MAM, with a particular attention concerning their roles in cellular homeostasis. Furthermore, we will discuss the important features to take into account when analyzing MAM integrity and function.

\section{Overview of molecular determinants of MAM}

The physical interaction between ER and mitochondria was suggested in 1959 (Copeland \& Dalton 1959) and for a long time, such observations have been suspected to be artifacts due to fixation. Then, MAM fractions were isolated in 1990 (Vance 1990) and further visualized in living cells using fluorescent proteins at the end of the 90s (Rizzuto et al. 1998). Since then, our knowledge on these contact sites and their molecular determinants of MAM has evolved with the improvement of imaging and analytic techniques, such as electron microscopy and electron tomography. Particularly, observation of MAM by wide-field digital 3D deconvolution microscope indicates that approximately $20 \%$ of the mitochondrial surface is in direct contact with the ER (Rizzuto et al. 1998, Friedman et al. 2011). The contact sites between the ER and mitochondria have been measured to be $10-30 \mathrm{~nm}$ wide (Csordas et al. 2006). A combined observation by electron microscopy and high-resolution three-dimensional electron tomography shows the presence of physical linkers between the two organelles (Friedman et al. 2011). Indeed, the two membranes of each organelle are closely apposed but do not fuse and thus each organelle maintains its identity. Proteins expressed at both membranes interact together, either directly or indirectly, thus forming multiprotein-tethering complexes. Interestingly, these proteins at the MAM interface have great varying functions, highlighting the crucial role of MAM in cellular homeostasis. All the proteins described so far as being localized at MAM interface in the literature are summarized in Fig. 1.

MAMs were firstly described as enriched in phospholipid (PL) enzymes such as phosphatidylserine (PS) synthase 1 and 2. Other lipid biosynthetic enzymes such as glycerol 3-phosphate acyltransferase, acylcoA synthase 4, diacylglycerol acyltransferase 2 and the microsomal triacylglycerol transfer protein are localized at MAM, regulating lipid, triacylglycerol and lipoprotein synthesis (for review, Vance 2014).

Another well-known protein complex identified at MAM interface is the $\mathrm{Ca}^{2+}$ channeling complex made of the inositol triphosphate receptor (IP3R) at the ER, the molecular chaperone glucose-regulated protein 75 (GRP75) and the voltage-dependent anion channel (VDAC) at the outer mitochondrial membrane. GRP75 was shown to be necessary and sufficient for the stimulatory effect of the IP3R on mitochondrial $\mathrm{Ca}^{2+}$ uptake. Silencing of Grp75 abolishes the functional coupling between IP3R1 and VDAC (Szabadkai et al. 2006, Tubbs et al. 2014), thereby reducing mitochondrial $\mathrm{Ca}^{2+}$ uptake (Szabadkai et al. 2006). Recently, another mitochondrial actor was shown to interact with and regulate this $\mathrm{Ca}^{2+}$ channeling complex, namely cyclophilin D (CYPD), a mitochondrial matrix protein which belongs to the family of the peptidyl-prolyl cis-trans isomerases and regulates the opening of the mitochondrial permeability transition pore in stressed conditions, particularly during myocardial

Published by Bioscientifica Ltd 


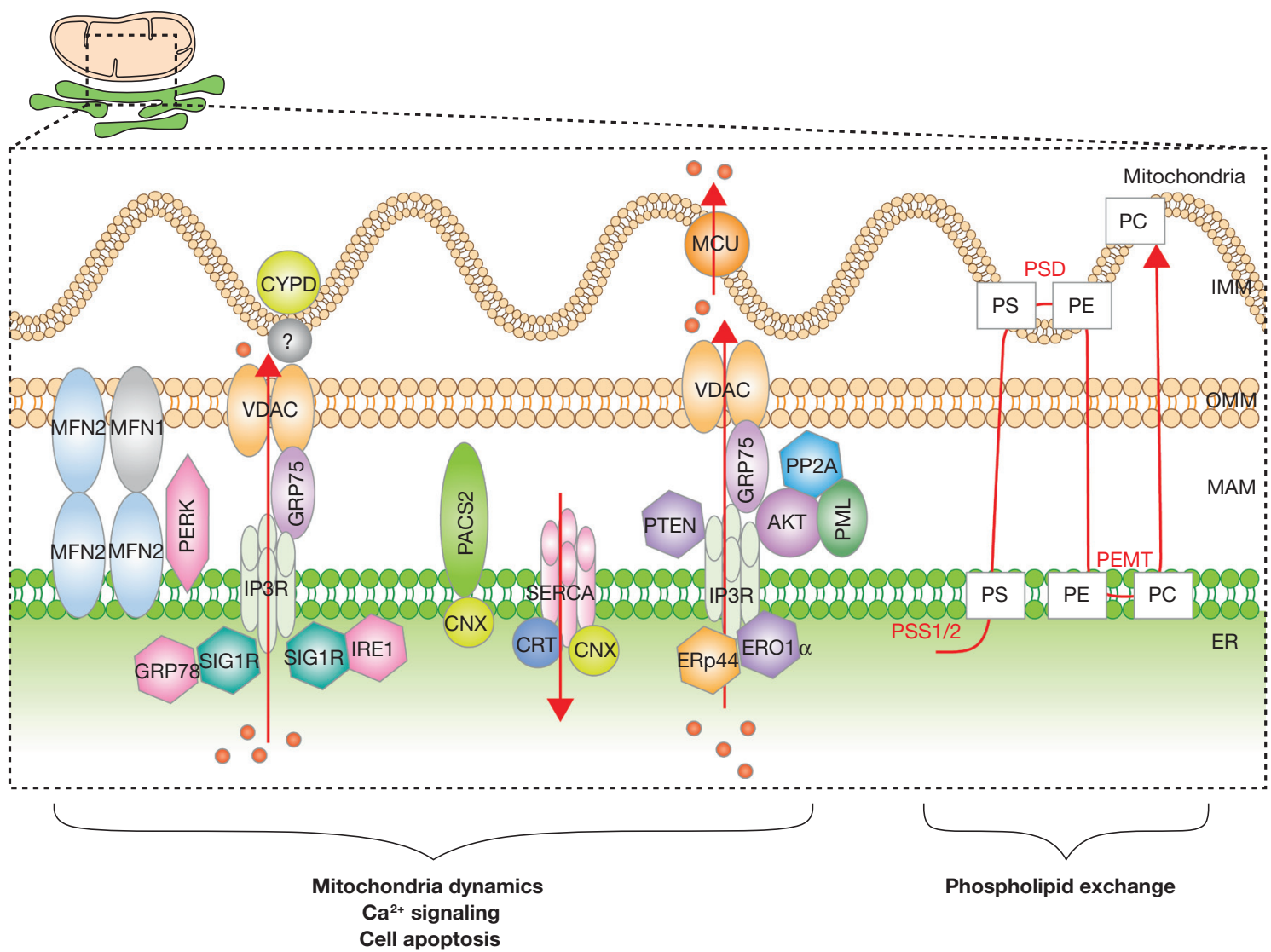

Figure 1

Schematic representation of ER-mitochondria contact sites and the established cellular signaling. Several proteins implicated in mitochondria dynamics, $\mathrm{Ca}^{2+}$ signaling, cellular apoptosis or phospholipid exchange at MAM interface are depicted. In yellow mitochondria and in green the ER, the red arrows correspond to calcium flux. ER, endoplasmic reticulum; IMM, inner mitochondrial membrane; MAM, mitochondria-associated membranes; OMM, outer mitochondrial membrane.

ischemia-reperfusion injury (Alam et al. 2015). CYPD was further identified at MAM interface, forming a high molecular complex with the IP3R-Grp75-VDAC complex in both cardiomyocytes and hepatocytes and regulating inter-organelle $\mathrm{Ca}^{2+}$ exchange (Paillard et al. 2013, Tubbs et al. 2014, Rieusset et al. 2016). It is likely that unknown interacting partners allow CypD to span mitochondrial membranes and interact with this complex.

Proteins involved in mitochondrial dynamics are also part of MAM. In fact, mitofusin 2 (MFN2), a mitochondrial protein controlling organelle fusion, was shown to be localized at both the outer mitochondrial membrane $(\mathrm{OMM})$ and at the ER, their binding forming a complex which tethers the ER to mitochondria (de Brito \& Scorrano 2008). Mfn 2 tethers regulate $\mathrm{Ca}^{2+}$ homeostasis at MAM as its genetic invalidation disrupted ER-mitochondria $\mathrm{Ca}^{2+}$ transfer (de Brito \& Scorrano 2008, Naon et al. 2016). In agreement, the mitochondrial ubiquitin ligase MITOL was reported to regulate ER-mitochondria interactions through
MFN2 ubiquitination (Sugiura et al. 2013). However, this widely accepted concept was recently challenged as both increased ER-mitochondria interactions and increased $\mathrm{Ca}^{2+}$ transfer were observed in Mfn2 knockout (KO) cells (Cosson et al. 2012, Filadi et al. 2015). The discrepancy between studies was suggested to be only apparent and related to analytical artifacts (Filadi et al. 2015). Additive studies are therefore required to clarify the precise role of MFN2 at MAM. Furthermore, ER-mitochondria contacts and $\mathrm{Ca}^{2+}$ signals are also critical for mitochondrial fission (Friedman et al. 2011, Korobova et al. 2013).

Phosphofurin acidic cluster-sorting proteins 2 (PACS2) is a multifunctional homeostatic regulator playing an important role in the trafficking of ion channels between secretory pathway compartments (Kottgen et al. 2005). PACS2 was identified at ER-mitochondria interface where it plays a role in sorting proteins on the ER and mitochondria (Simmen et al. 2005). PACS2 depletion disrupts mitochondria structure and ER homeostasis, 
leading to stress-mediated uncoupling of the organelles and to the inhibition of $\mathrm{Ca}^{2+}$ signal transmission (Simmen et al. 2005). Conversely, overexpression of PACS2 was shown to increase ER-mitochondria interaction and $\mathrm{Ca}^{2+}$ exchange in liver (Arruda et al. 2014), confirming that the presence of PACS2 is sufficient to control MAM integrity and function. Furthermore, PACS2 was shown to be phosphorylated on Ser437 by AKT and to control TRAIL-induced apoptosis (Aslan et al. 2009), but the involvement of MAM in this process is still unclear. Lastly, PACS2 regulates the activity of calnexin (CNX), an ER chaperone compartmentalized in MAM and modulating local $\mathrm{Ca}^{2+}$ by regulating the activity of sarco/endoplasmic reticulum $\mathrm{Ca}^{2+}$-ATPase (SERCA). In physiological conditions, more than $80 \%$ of CXN localize to the ER, mostly in MAM. In fact, Pacs2 knockdown causes a redistribution of CXN away from the ER, to the plasma membrane, therefore affecting mitochondrial and ER Ca ${ }^{2+}$ homeostasis (Rizzuto et al. 2012).

Hayashi and coworkers identified the ER-resident sigma 1 receptor (SIG1R) as a novel 'ligand-operated' chaperone that specifically targets MAM (Hayashi \& Su 2007). They found that SIG1R forms a complex with another ER chaperone, the $78 \mathrm{kDa}$ glucose-regulated protein (GRP78, also known as BIP). SIG1R/GRP78 complex forms a $\mathrm{Ca}^{2+}$-sensitive chaperone machinery and extends $\mathrm{Ca}^{2+}$ signaling from the ER into mitochondria by stabilizing IP3R at MAM. Furthermore, SIG1R is upregulated and redistributed by ER stress. Depletion of $\mathrm{ER} \mathrm{Ca}^{2+}$ triggers SIG1R to dissociate from GRP78 to bind to IP3Rs. More recently, Hayashi's group further showed that Sig-1R at MAM can stabilize the inositol-requiring protein 1 (IRE1) and enhance the cellular survival by prolonging the activation of the IRE1 signaling pathway (Mori et al. 2013). Taken together, these results suggest that SIG1R has a pivotal role at MAM interface in IP3R-mediated mitochondrial $\mathrm{Ca}^{2+}$ influx and cellular survival after ER stress.

In addition, the promyelocytic leukemia (PML) tumor suppressor also controls cell survival by regulating $\mathrm{Ca}^{2+}$ signaling at MAM interface. Indeed, Giorgi and coworkers analyzed PML intracellular localization by cell fractionation and identified the presence of PML in both ER and MAM fractions (Giorgi et al. 2010). The presence of PML at MAM was shown to control protein phosphatase 2A (PP2A)- and AKT-dependent modulation of IP3R phosphorylation and in turn IP3R-mediated $\mathrm{Ca}^{2+}$ release from ER. Loss of $P m l$ resulted in a decreased $\mathrm{Ca}^{2+}$ release from the ER and a subsequent lower $\mathrm{Ca}^{2+}$ influx into mitochondria. More recently, the same group further demonstrated that PML inhibited autophagy at MAM interface in a $\mathrm{Ca}^{2+-d e p e n d e n t ~ m a n n e r ~(M i s s i r o l i ~ e t ~ a l . ~}$ 2016). Loss of Pml therefore activates autophagy and promotes cell survival upon stress. Therefore, the authors suggested that blocking autophagy should restore the activity of chemotherapy in PML-downregulated tumors.

Beyond these established actors at MAM interface, recent proteomic analyses have increased our knowledge on molecular components of MAM, highlighting new cellular functions. Until now, three studies have analyzed protein content of MAM fraction by proteomic analyses (Poston et al. 2011, Zhang et al. 2012, Sala-Vila et al. 2016). Poston and coworkers have identified 250 proteins in MAM in NG108/105 cells (a cholinergic neuroblastomaglioma hybrid cell line) and confirmed the presence of the above-mentioned proteins. Interestingly, the numerous other proteins found at MAM interface seem, primarily, to be involved in metabolic and protein processing activities. Zhang and coworkers also performed a proteomic analysis of the MAM proteome in uninfected and HCMV-infected human foreskin fibroblasts and showed that HCMV infection modulated 991 proteins at MAM interface, selectively modulating MAM functional activities. Lastly, Sala-Vila and coworkers recently reported a proteomic analysis of MAM from mouse liver and identified calveolin 1 (CAV1) as an important component of this subdomain controlling its relative cholesterol content. Differential proteomics analysis between MAM from wild-type (wt) and CAV1-deficient mice suggests that CAV1 participates in intracellular steroid and lipoprotein metabolismrelated processes at MAM.

\section{Established cellular functions of MAM}

Until now, the most described functions of ER-mitochondria interactions are lipid biosynthesis, $\mathrm{Ca}^{2+}$ transfer and response to cellular stress, key cellular processes that are involved in life and death events. These functions have been largely reviewed (Marchi et al. 2014, Naon \& Scorrano 2014, van Vliet et al. 2014, Giorgi et al. 2015a) and will not be described in detail here.

Briefly, the close juxtaposition between ER and mitochondria has been firstly implicated in the exchange of PL between organelles (Vance 1990). PL synthesis is usually restricted to ER. Therefore, they must be transported from ER to the membranes of other organelles. One mechanism of PL transport between ER and mitochondria is via membrane contact sites. Indeed, PS is synthesized in ER of mammalian cells by the exchange of serine for the choline or ethanolamine head-groups of phosphatidylcholine

Published by Bioscientifica Ltd 
or phosphatidylethanolamine (PE) by PS synthase- 1 and PS synthase-2, which are enriched at MAM. Then, newly made PS is transferred into mitochondria through MAM, where it is decarboxylated to PE via PS decarboxylase in mitochondrial inner membrane. $\mathrm{PE}$ is also produced at MAM by acylation of lyso-PE by lyso-PE acyltransferase.

Later, another important function was discovered: a quasi-synaptic mechanism of $\mathrm{Ca}^{2+}$ transmission (Rizzuto et al. 1998). The ER was known for a long time as the main $\mathrm{Ca}^{2+}$ store of the cell, whereas mitochondria were also shown to accumulate $\mathrm{Ca}^{2+}$. When the basal concentration of cytosolic $\mathrm{Ca}^{2+}$ rises (typically $\sim 100 \mathrm{nM}$ ), the mitochondrial $\mathrm{Ca}^{2+}$ concentrations can increase almost simultaneously to as much as $10 \mathrm{mM}$ (Rizzuto \& Pozzan 2006). This was an unexpected observation by Rizzuto and coworkers $(1993,1998)$ considering the low affinity to $\mathrm{Ca}^{2+}$ of the mitochondrial $\mathrm{Ca}^{2+}$ uniporter. Moreover, $\mathrm{Ca}^{2+}$ released by the ER into the cytosol in response to IP3 is transferred to mitochondria much more efficiently than cytosolic $\mathrm{Ca}^{2+}$ elevations induced by leakage of $\mathrm{Ca}^{2+}$ from this organelle (Rizzuto et al. 1993, Hajnoczky et al. 1995). These observations led to the proposal by Rizzuto and Pozzan of the existence of close contact points between ER and mitochondria, enriched in IP3R and RYR. Therefore, the release of high $\mathrm{Ca}^{2+}$ concentrations at contact sites between the two organelles leads to the formation of microdomains of high $\mathrm{Ca}^{2+}$ concentration that are crucial for efficient $\mathrm{Ca}^{2+}$ uptake by mitochondria (Rizzuto et al. 1993, 1998). One of the main functions of $\mathrm{Ca}^{2+}$ uptake by mitochondria is to activate intramitochondrial dehydrogenases (Eriksson et al. 1998), leading to the activation of mitochondrial metabolism and energy production.

The movement of $\mathrm{Ca}^{2+}$ between the ER and mitochondria is an essential component of the cell survival processes. When MAMs are disrupted, the release of $\mathrm{Ca}^{2+}$ from the ER mediated by IP3R is suppressed and ATP production and cell survival are reduced (Rowland \& Voeltz 2012). Similarly, apoptosis is attenuated in cells that are partially depleted of IP3Rs (Jayaraman \& Marks 1997). At the opposite, apoptosis occurs when excess $\mathrm{Ca}^{2+}$ flow out of the ER into mitochondria via the IP3R, which are highly concentrated in MAM (Rizzuto et al. 1993, 1998). The flow of $\mathrm{Ca}^{2+}$ from the ER into mitochondria promotes the oligomerization of BAX (a pro-apoptotic protein of OMM) and causes permeabilization of OMM. In consequence, cytochrome $\mathrm{c}$ is released into the cytosol where the caspase cascade is activated and ultimately, apoptosis is induced (Scorrano et al. 2003). The $\mathrm{Ca}^{2+}$-mediated activation of the mitochondrial fission protein, DRP1, also stimulates BAX oligomerization and increases apoptosis (Hoppins \& Nunnari 2012). Apoptosis is also induced upon depletion of PACS2, the MAMassociated multifunctional sorting protein. Depletion of Pacs2 dissociated the ER from mitochondria and induced extensive mitochondrial fragmentation (Simmen et al. 2005). In agreement, when mitochondrial fusion is increased, apoptosis is attenuated (Frank et al. 2001). Taken together, the disruption of MAM and the corresponding increase in mitochondrial fission/fragmentation are associated with the induction of apoptosis.

\section{Important structural features to take into account when analyzing MAM}

Beyond the molecular determinants of MAM, several important structural features have to be considered when we talk about MAM, including the frequency of organelle contact, the spacing between both organelles and the contact size/volume, as all these parameters could be extremely variable from one study to another, depending on the cellular context and the technology used to study MAM.

Frequency It was initially suggested that $80 \%$ of mitochondria are in contact with ER in the liver (Montisano et al. 1982). Later, more sophisticated analytical techniques revised downward this frequency and found that around 20\% of mitochondria are in contact with ER at least in Hela cells (Rizzuto et al. 1998). However, MAMs are very dynamic structures and the amount of mitochondria in contact with the ER can widely vary.

Spacing The distance between ER and mitochondria was originally estimated to be about $100 \mathrm{~nm}$ (Soltys et al. 1992), whereas more sophisticated approaches have shown that it can be even smaller, up to $10 \mathrm{~nm}$ at the smooth ER and $25 \mathrm{~nm}$ at the rough ER (Csordas et al. 2006). This close proximity of ER with the OMM supports the interaction between proteins localized on opposing membrane faces. The distance between both organelles regulates MAM function (Giacomello \& Pellegrini 2016) as $\mathrm{Ca}^{2+}$ transfer from ER to mitochondria is optimal at $15 \mathrm{~nm}$ and reduced at $5 \mathrm{~nm}$ (Csordas et al. 2010). In agreement, disruption of ER-mitochondria physical interactions through invalidation of MAM proteins is often associated with loss of MAM function, such as $\mathrm{Ca}^{2+}$ transfer or lipid synthesis (Simmen et al. 2010).

Published by Bioscientifica Ltd. 
Spacing Lastly, it is noteworthy that these contact zones between ER and mitochondria could be more or less distant. They can be occasional, meaning that a small proportion of mitochondria membrane is in contact with the ER (Rizzuto et al. 1998). Otherwise, the ER can constrict entirely mitochondria, notably for mitochondria division (Friedman et al. 2011). Furthermore, the length of these tethers can be dynamically regulated as it was shown that apoptotic agents are able to narrow the ER-mitochondria gap (Csordas et al. 2006).

ER-mitochondria contacts are variable, and it is unclear if all connections between both organelles consistently have the same protein composition. Furthermore, it seems that modulation of the expression of several proteins at the MAM interface is sufficient to destabilize ER-mitochondria interactions. This is the case for PACS2 (Simmen et al. 2005, Arruda et al. 2014), SIG1R (Hayashi \& Su 2007), IP3R1 (Arruda et al. 2014), GRP75 (Szabadkai et al. 2006, Tubbs et al. 2014), MFN2 (de Brito \& Scorrano 2008, Tubbs et al. 2014) and CYPD (Rieusset et al. 2016). Therefore, these data suggest that several proteins are involved in MAM stabilization or formation. However, no MAM protein is exclusively expressed at MAM; therefore, the modulation of their expression could have unspecific effects beyond MAM.

Altogether, these data mean that these features of MAM should be considered with the highest caution when analyzing ER-mitochondria communication in health and diseases. Nevertheless, it raises the intriguing possibility that the ER-mitochondria distance could be controlled to affect ER-mitochondria function.

\section{New functions of MAM in cellular metabolic homeostasis}

The importance of $\mathrm{Ca}^{2+}$ signaling and mitochondrial metabolism in various cellular signaling pathways highlights the importance of MAM for metabolic homeostasis. New functions of MAM in hormonal and nutrient signaling recently emerged, thus highlighting the dynamic regulation of ER-mitochondria interactions in function of energy state and nutrient status. Furthermore, metabolic homeostasis is dependent on proper signaling pathways from ER, such as the unfolded protein response (UPR) and the autophagy, both controlled by MAM integrity and by MAM actors. Here, we review the recent studies demonstrating that MAM could be an important hub for several signaling pathways controlling metabolic homeostasis (Fig. 2 and Table 1).

\section{Role of MAM in energy metabolism and redox status}

Metabolic homeostasis is dependent on both energy and redox status, as they control the activity of numerous metabolic enzymes. Interestingly, ER-mitochondria interactions were involved in the control of both energy metabolism and redox status, thus pointing at MAM as an important hub for metabolic homeostasis.

The transfer of $\mathrm{Ca}^{2+}$ from ER to mitochondria is crucial for the control of mitochondria energy metabolism. Indeed, mitochondrial $\mathrm{Ca}^{2+}$ levels control the activity of three deshydrogenases of Krebs cycle (Denton 2009), thus influencing ATP synthesis. In agreement, increased ER-mitochondrial coupling was shown to promote mitochondrial respiration and bioenergetics during early phases of ER stress (Bravo et al. 2011). Conversely, genetic or pharmacological inhibition of IP3R altered mitochondrial function, lowering ATP production and triggering autophagy (Cardenas et al. 2010). Thus, IP3R-mediated $\mathrm{Ca}^{2+}$ release is important for cellular bioenergetics. Furthermore, this bioenergetic response seems important for cellular adaptation during early stage of ER stress as moderate ER stress increased ER-mitochondria interactions to increase $\mathrm{Ca}^{2+}$ transfer and enhance mitochondrial respiration (Bravo et al. 2011). However, sustained activation of ER stress impaired mitochondrial metabolism (Wang \& Pantopoulos 2011), suggesting a strong link between metabolic insufficiency and ER stress-mediated apoptosis.

Some enzymes involved in ER redox regulation are found at MAM interface, such as the ER oxidoreductase 1 alpha (ERO1 $\alpha$ ) (Gilady et al. 2010, Anelli et al. 2012, Lynes et al. 2012). This protein is important for the formation of disulfide bonds within newly synthesized polypeptides (Hatahet \& Ruddock 2009). The localization of ERO1 $\alpha$ on the MAM is dependent on oxidizing conditions within the ER (Gilady et al. 2010) and was shown to potentiate the release of $\mathrm{Ca}^{2+}$ during ER stress (Li et al. 2009). In addition, several chaperones important for protein folding are present at MAM interface and regulate either IP3R or SERCA (Simmen et al. 2010). Therefore, ER oxidative protein folding is an important regulator of $\mathrm{Ca}^{2+}$ homeostasis and signaling.

\section{Role of MAM in insulin signaling}

Insulin is a key hormone of post-prandial metabolism controlling blood glucose levels through a signaling pathway composed of IRS-PI3K-AKT.

Published by Bioscientifica Ltd. 


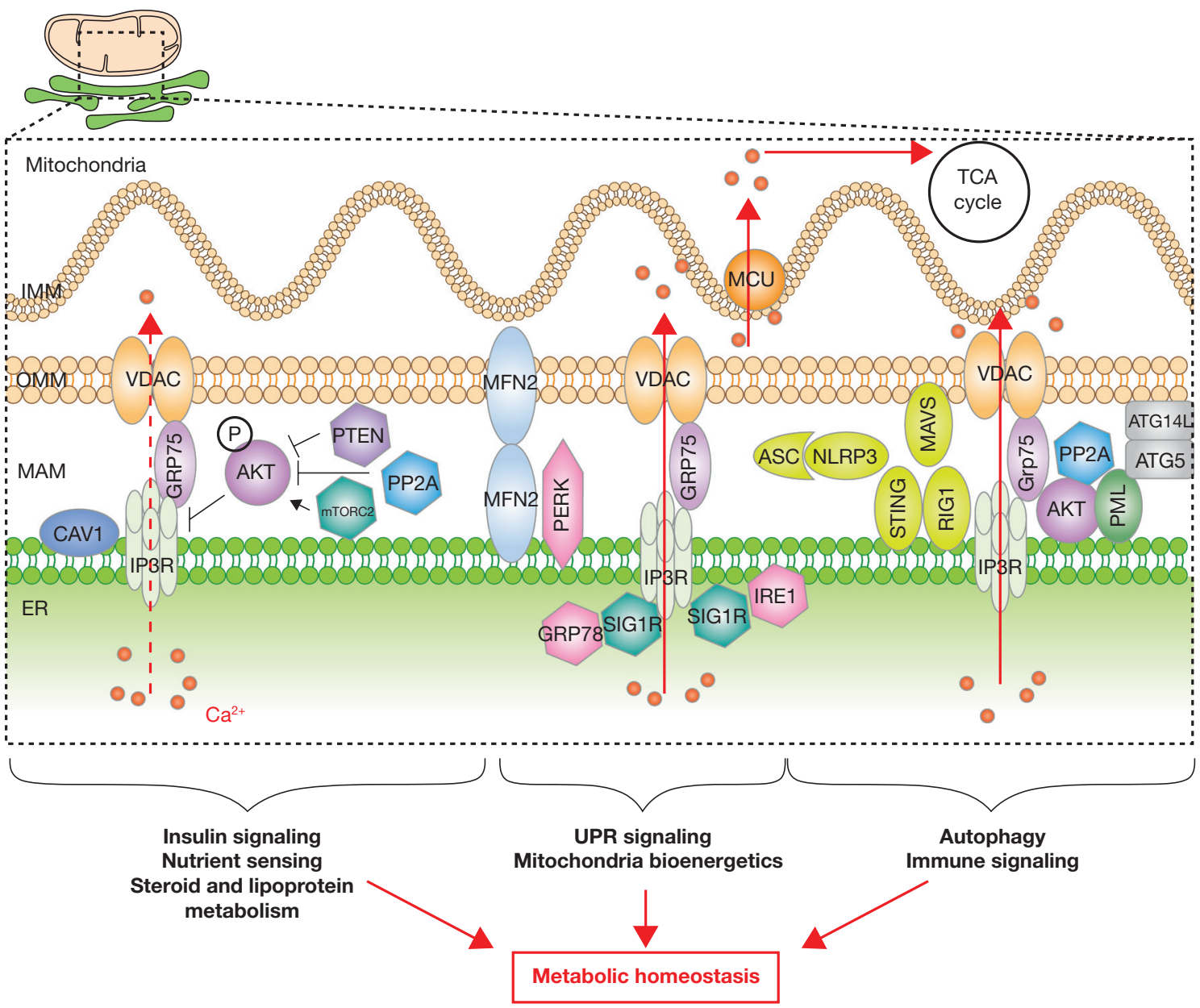

Figure 2

MAM is an important hub for several signaling pathways controlling metabolic homeostasis. The new role of MAM in insulin and nutrient signaling and in steroid and lipoprotein metabolism, as well as their role in unfolded protein response (UPR) signaling, mitochondria bioenergetics, autophagy and in immune signaling, participating to the control of metabolic homeostasis.

Several insulin signaling proteins were recently identified at MAM interface, suggesting that MAM could be an important hub for insulin signaling. Indeed, the protein kinase AKT (also called $\mathrm{PKB}$ ) was found to interact with the PML/PP2A/IP3R complex in MAM fractions (Giorgi et al. 2010) and controlled ER $\mathrm{Ca}^{2+}$ release. The phosphorylation of IP3R by AKT reduced cellular sensitivity to apoptotic stimuli through a mechanism that involved diminished $\mathrm{Ca}^{2+}$ flux from the ER to mitochondria (Szado et al. 2008). The presence of AKT at MAM seems to regulate MAM integrity as ER-mitochondria interactions are reduced in Akt KO cells (Betz et al. 2013). Importantly, an increase of phosphorylated AKT (active form) was found in the liver of obese and diabetic mice (Tubbs et al. 2014), associated with a disruption of MAM, confirming an interplay between AKT and MAM integrity. However, the exact role of AKT at MAM in the control of insulin action requires further investigations. Furthermore, mammalian target of rapamycin complex 2 (mTORC2), another kinase important for cellular metabolism, was found at MAM interface (Betz et al. 2013). Similar to AKT, loss of mTORC2 disrupted ER-mitochondria interactions (Betz et al. 2013). mTORC2 localization to MAM is stimulated by growth factors and insulin and controls AKT phosphorylation as well as the phosphorylation of its targets PACS2, IP3R and hexokinase 2 (Betz et al. 2013). Therefore, MAM could be considered as a hub for mTORC2-AKT signaling. Lastly, phosphatase and tensin homolog deleted on chromosome 10 (PTEN), another protein controlling AKT activity, was identified at MAM interface (Bononi et al. 2013). PTEN was shown to interact with IP3R at MAM and to increase $\mathrm{Ca}^{2+}$ transfer from the ER to mitochondria through its protein phosphatase activity (Bononi et al. 2013). As this situation is associated with 
Table 1 Summary of the most important proteins with metabolic signaling functions at MAM discussed in this review.

\begin{tabular}{|c|c|}
\hline Proteins & Localization \\
\hline AKT & cyt, MAM \\
\hline mTORC2 & cyt, MAM \\
\hline PTEN & cyt/mt/MAM \\
\hline PP2A & cyt, ER, MAM \\
\hline CYPD & $\mathrm{mt} / \mathrm{MAM}$ \\
\hline
\end{tabular}

Functions

Activator of insulin signaling pathway antiapoptotic function inhibits $\mathrm{Ca}^{2+}$ release from ER MAM interactors IP3R, PACS2, HKII, PP2A, PML, PTEN, MTORC2

Szado et al. (2008)

Giorgi et al. (2010)

Betz et al. (2013)

Tubbs et al. (2014)

Regulator of MAM integrity

Serine/threonine kinase

Activator of Akt

Activator of insulin

signaling pathway

Regulates $\mathrm{mt} \mathrm{Ca}^{2+}$ uptake

and bioenergetics

Regulator of MAM integrity

Protein and lipid phosphatase

Negative regulator of AKT

Negative regulator of insulin signaling pathway

Regulates ER Ca2+ release

Proapoptotic function

Serine/threonine phosphatase

Negative regulator of AKT

Negative regulator of insulin signaling pathway

Involved in glucosemediated reduction of ER-mt interactions

Regulator of mPTP opening

Regulator of MAM integrity

Regulator of ER-mt $\mathrm{Ca}^{2+}$ transfer

Loss of CYPD induces hepatic insulin resistance and protects cardiomyocytes from hypoxia/reoxygenation injury

MFN2

$\mathrm{mt} / \mathrm{ER} / \mathrm{MAM}$

Regulator of $\mathrm{mt}$ fusion

Regulator of liver and muscle insulin sensitivity

Regulator of MAM integrity

Regulator of ER-mt $\mathrm{Ca}^{2+}$ transfer

GRP78

ER/MAM

ER chaperone

Stabilizes IP3R at MAM Involved in unfolded protein response

Is stabilized at the MAM by SIG1R when cells are under ER stress
AKT, PACS2

Betz et al. (2013)

AKT, IP3R

Bononi et al. (2013)

PML, AKT, IP3R

Giorgi et al. (2010)

Theurey et al. (2016)

IP3R-GRP75-VDAC complex

Paillard et al. (2013)

Tubbs et al. (2014)

Rieusset et al. (2016)

Theurey et al. (2016)

MFN1, PERK

de Brito \& Scorrano (2008)

Cosson et al. (2012)

Filadi et al. (2015)

Naon et al. (2016)

Sebastian et al. (2012)

SIG1R

Hayashi \& Su (2007)

SIG1R

Mori et al. (2013) 
Proteins

PERK

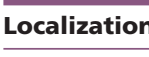

ER/MAM

ATG14L and ATG5

cyt/MAM

ER/MAM

STING

NLRP3

mt/MAM

\begin{tabular}{l} 
Functions \\
\hline Protein kinase involved in \\
unfolded protein \\
response \\
Increases ER- \\
mitochondria \\
interactions \\
Regulator of autophagy \\
Enriched at MAM after \\
starvation \\
Regulator of innate \\
immune signaling \\
Regulator of innate \\
immune signaling \\
Regulator of \\
inflammasome \\
activation
\end{tabular}

MAM interactors

MFN2

References

Verfaillie et al. (2012)

Munoz et al. (2013)

STX17

Hamasaki et al. (2013)

MFN2

Horner et al. (2011)

Ishikawa et al. (2009)

ASC

Zhou et al. (2011)

cyt, cytoplasm; ER, endoplasmic reticulum; MAM, mitochondria-associated membranes; mt, mitochondria.

reduced phosphorylated AKT at MAM, PTEN could control ER-mitochondria $\mathrm{Ca}^{2+}$ transfer by counteracting AKT activation and AKT-mediated phosphorylation of IP3R.

Recently, MAM integrity was further shown to control directly insulin action in hepatocytes (Tubbs et al. 2014). Indeed, it was shown that experimental disruption of MAM altered insulin signaling and action in hepatocytes, whereas overexpression of MAM proteins enhanced it (Tubbs et al. 2014), demonstrating that MAM integrity controls insulin action. Similarly, pharmacological alteration of mitochondrial $\mathrm{Ca}^{2+}$ uptake was shown to disrupt insulin signaling in cardiomyocytes (Gutierrez et al. 2014). Conversely, loss of Akt or mTorc2 disrupted MAM integrity (Betz et al. 2013), suggesting a reciprocal relationship between MAM and insulin signaling. However, the molecular mechanisms underlying this relationship are still unclear. Future investigations will determine whether MAMs control the canonical insulin signaling pathways in the cytosol or whether insulin signaling requires to transit at the MAM interface.

\section{Role of MAM in nutrient signaling}

Both ER and mitochondria are now considered as nutrient sensors allowing adaptation of cellular metabolism. Interestingly, MAM interface could also act as a nutrientregulated hub to adapt mitochondrial metabolism.

Several recent studies suggest that MAMs are dynamically regulated by the energetic state of the cell. Indeed, ER-mitochondria contacts were shown to increase twice in length in the liver when nutrients become limiting and to re-modulate mitochondria cristae by a mechanism involving OPA1 and MFN2 (Sood et al. 2014), suggesting that MAM can help mitochondria to adapt to metabolic transitions. In agreement, disruption of MAM inhibits starvation-induced autophagy by inhibiting the PS transfer from ER to mitochondria-derived autophagosomes (Hailey et al. 2010), supporting the role of MAM in starvation-induced processes. Conversely, our laboratory further demonstrated that MAM integrity is reduced after feeding in liver, a regulation reproduced by increasing blood glucose levels (Theurey et al. 2016). In agreement, high glucose levels reduced ER-mitochondria interactions and $\mathrm{Ca}^{2+}$ exchange in $\mathrm{HuH} 7$ cells, pointing toward glucose as a major regulator of MAM integrity in high-energy state. At the molecular level, we revealed that high glucose levels disrupted MAM integrity and function through the pentose phosphate (PP)-PP2A pathway, and subsequently induced mitochondria fragmentation and altered mitochondria respiration (Theurey et al. 2016). Altogether, these data point at MAM as a glucose sensor to adapt cellular bioenergetics, likely contributing to the adaptive fuel partitioning during nutritional transition. The capacity to switch from lipid to glucose oxidation during the transition from a fasted to a fed state is called metabolic flexibility, and metabolic inflexibility was associated with ectopic lipid accumulation and insulin resistance (Galgani et al. 2008). Therefore, the capacity of MAM to connect energy sensing to mitochondria physiology plays a crucial role for the control of glucose homeostasis.

The mechanism by which the phosphatase PP2A could control the glucose-mediated reduction of ERmitochondria interactions is still unclear. As PP2A was shown to control AKT phosphorylation and $\mathrm{Ca}^{2+}$ release by IP3R at MAM interface (Giorgi et al. 2010), this regulation could depend on phosphorylation state of yet-to-be identified substrates at MAM. We suggest that

Published by Bioscientifica Ltd 
high glucose levels could reduce the presence of PP2A at MAM interface, as an increase of phosphorylated AKT (Tubbs et al. 2014) and an increase of the presence of mTORC2 (Betz et al. 2013) were observed at MAM after insulin stimulation or refeeding in liver.

\section{Role of MAM in UPR signaling}

ER plays a key rolein the folding of proteins. Compromising this ER function leads to the accumulation of misfolded proteins, which triggers an adaptive ER response called the unfolded protein response (UPR). The UPR is known to upregulate chaperones, to inhibit protein synthesis, to enhance degradation of misfolded proteins and to expand the ER (Schroder 2008). ER stress is sensed predominantly by three ER transmembrane proteins, namely double-stranded RNA-activated protein kinaselike ER kinase (PERK), IRE1 $\alpha$ and activating transcription factor 6 (ATF6), which subsequently activate different signaling pathways aiming at promoting cell survival. Interestingly, activation of UPR also controls insulin signaling pathways (Salvado et al. 2015), suggesting that the control of UPR by MAM could indirectly influence metabolic homeostasis.

Firstly, several proteins of the UPR were shown to be present in MAM fractions. Indeed, both GRP78 and IRE1 were involved in interactions with SIG1R to facilitate inter-organelle signaling for survival (Hayashi \& Su 2007, Mori et al. 2013). Another actor of the UPR found at MAM is PERK, which plays a key role in organelle tethering, controlling ROS transfer and apoptosis (Verfaillie et al. 2012). Loss of PERK reduced ER-mitochondria interactions and disrupted ER morphology and $\mathrm{Ca}^{2+}$ signaling. Furthermore, MFN2 was shown to physically interact with PERK to negatively regulate its activity (Munoz et al. 2013). These authors showed that the silencing of PERK partially rescued mitochondria fragmentation and aberrant mitochondrial $\mathrm{Ca}^{2+}$ content caused by loss of Mfn2. However, further studies are required to determine whether PERK-mediated effects on mitochondria are dependent on its presence at the MAM interface.

Furthermore, the initial adaptive phase of ER stress was shown to be associated with an increase of ERmitochondria interactions (Bravo et al. 2011), likely to increase energy synthesis, which is required for the proper folding of proteins. Conversely, MAM integrity further controls the activation of UPR and subsequent ER stress. Indeed, the genetic invalidation of several MAM proteins, such as PACS2 (Simmen et al. 2005), SIG1R (Hayashi \& Su 2007), MFN2 (Sebastian et al. 2012) or
CYPD (Rieusset et al. 2016) were shown to concomitantly induce MAM disruption and ER stress.

\section{Role of MAM in autophagy}

Starvation-induced autophagy is a cellular catabolic process degrading cellular constituents to generate energy in period of scarcity (Kaur \& Debnath 2015). Therefore, autophagy plays an important regulatory role in metabolic homeostasis. In agreement, impaired autophagy is associated with hepatic steatosis (Lavallard \& Gual 2014), whereas suppression of autophagy leads to hepatic ER stress and insulin resistance (Yang 2010).

Interestingly, autophagosome formation was shown to occur at MAM interface (Hamasaki et al. 2013). The authors demonstrated that different proteins of autophagy (ATG14L and ATG5) were enriched at MAM after starvation (Hamasaki et al. 2013). Interestingly, the disruption of MAM by knocking down Pacs2 or Mfn2 decreases the number of autophagosomes, suggesting that MAM integrity is a requirement for autophagosome formation. According to this model, disruption of MAM by $M f n 2-K O$ inhibits lipid transfer and starvationinduced autophagy by inhibiting the PS transfer from ER into mitochondria-derived autophagosomes (Hailey et al. 2010). Interestingly, two proteins that are present at MAM interface were recently shown to regulate autophagy; PML inhibits autophagy at MAM interface by a $\mathrm{Ca}^{2+-d e p e n d e n t ~ m e c h a n i s m ~(M i s s i r o l i ~ e t ~ a l . ~ 2016), ~}$ whereas PP2A dephosphorylates Unc-51-like autophagy activating kinase 1 and induces autophagy (Wong et al. 2015). Although both PML and PP2A interact together at MAM (Giorgi et al. 2010), it is still unclear whether the regulation of autophagy by $\mathrm{PP} 2 \mathrm{~A}$ involves its presence at MAM interface.

\section{Role of MAM in immune signaling}

Immune responses and metabolic regulation are tightly coupled, and prolonged or exacerbated inflammatory responses have been associated with metabolic diseases (Chassaing et al. 2014, Delzenne et al. 2015, Lackey \& Olefsky 2016). Therefore, the recent involvement of MAM in immune signaling supports a role of MAM in metabolic homeostasis.

Several proteins involved in immune response to DNA viruses, such as the mitochondrial antiviralsignaling protein (MAVS) (Horner et al. 2011) or the stimulator of interferon genes (STING) (Ishikawa et al. 2009) were shown to be localized at MAM. Indeed,

Published by Bioscientifica Ltd. 
retinoic acid-inducible gene 1 is recruited at MAM during viral infection and binds to MAVS to initiate a signaling cascade leading to the upregulation of proinflammatory cytokines. This process is supported by the ER-mitochondria tethering function of MFN2 (Horner et al. 2011). Interestingly, the hepatitis C virus NS3/4A protease, involved in the cleavage of MAVS to inhibit a strong antiviral response, was shown to target MAM (Horner et al. 2011), highlighting the role of MAM in the regulation of innate immune signaling.

Autophagy and inflammasome activation are intimately linked and mutually influence each other (Martins-Marques et al. 2015). In agreement with the role of MAM in the autophagosome formation, MAMs were also shown to be important for the inflammasome activation. Indeed, NOD-like receptor pyrin domaincontaining 3 (NLRP3) protein and its adaptator ASC co-localized to the MAM fractions following the activation of the NLRP3 inflammasome by nigericin or monosodium urate (Zhou et al. 2011). Although mitochondrial ROS are required for the activation of inflammasome (Tschopp 2011), the exact molecular mechanisms by which MAMs regulate immune signaling are still unclear.

\section{Role of ER-mitochondria miscommunication in metabolic diseases}

Given the important role of MAM structure and function in the control of numerous signaling pathways regulating metabolic homeostasis, it is not surprising that ER-mitochondria miscommunication participates to metabolic diseases (Fig. 3).

\section{ER-mitochondria miscommunication and insulin resistance}

The potential involvement of ER-mitochondria communication in hepatic insulin resistance was firstly suggested by a study highlighting a strong relationship between ER stress and mitochondria dysfunction. Indeed, experimental mitochondrial dysfunction was shown to induce ER stress through an elevation of cytosolic free $\mathrm{Ca}^{2+}$ and led subsequently to aberrant insulin signaling and increased hepatic gluconeogenesis (Lim et al. 2009). In agreement, liver-specific $\mathrm{KO}$ of the mitochondrial Mfn2 (Sebastian et al. 2012) or loss of the mitochondrial CypD (Rieusset et al. 2016) induced both hepatic ER stress and insulin resistance, whereas cells deficient in the three isoforms of IP3R in ER showed mitochondrial dysfunction (Cardenas et al. 2010), thus confirming an interplay between ER and mitochondria dysfunction in the context of metabolic diseases.

Our group investigated the involvement of MAM disruption in hepatic insulin resistance (Tubbs et al. 2014). We found that MAM integrity is altered in palmitate-induced insulin-resistant $\mathrm{HuH7}$ cells, as well as in liver of different models of obese and diabetic mice (ob/ob and high-fat and high-sucrose diet (HFHSD)fed mice). Importantly, disruption of MAM integrity by genetic or pharmacological inhibition of CYPD induced insulin resistance in mice and disrupted insulin signaling in human primary hepatocytes. Interestingly, treatment of diabetic mice with antidiabetic drugs (HFHSD mice with rosiglitazone or CypD-KO mice with metformin) improved insulin sensitivity and restored organelle communication. Conversely, the rescue of MAM integrity in primary hepatocytes of $o b / o b$ or HFHSD mice by adenoviral overexpression of $C y p D$ improved insulin action confirming a key role of ERmitochondria miscommunication in hepatic insulin resistance (Tubbs et al. 2014). Other independent observations support a link between disrupted MAM and hepatic insulin resistance. For example, ER-mitochondria interactions were disrupted after cellular loss of $m$ Torc2 (Betz et al. 2013), whereas mice with liver-specific KO of rictor, a mTORC2 subunit, showed impaired glucose and lipid homeostasis (Hagiwara et al. 2012). Similarly, loss of Mfn2 induced reduced ER-mitochondria interactions in pro-opiomelanocortin (POMC) neurons, whereas hepaticspecific loss of $M f n 2$ in mice induced hepatic insulin resistance and altered glucose homeostasis (Sebastian et al. 2012). Interestingly, overexpression of the constitutive active AKT2 restored glucose fluxes and lipogenesis in mTORC2-deficient hepatocytes (Hagiwara et al. 2012), whereas overexpression of $M f n 2$ improved HFD-induced insulin resistance (Gan et al. 2013), suggesting that both mTORC2-AKT and MFN2 are important for metabolic homeostasis. However, whether these effects involve modulations of MAM is still unclear.

Mechanistically, we suggest that a loss of $\mathrm{Ca}^{2+}$ transfer from ER to mitochondria links MAM disruption to hepatic insulin resistance. In the case of CypD-KO mice, the disruption of $\mathrm{Ca}^{2+}$ exchange between both organelles leads to organelle stress, lipid accumulation, activation of protein kinase $\mathrm{C} \varepsilon$ and alteration of insulin-stimulated AKT phosphorylation (Rieusset et al. 2016). Whether this mechanism can be generalized to genetic and nutritional models of obesity and T2DM has to be determined. Interestingly, ER-mitochondria contacts are also reduced in POMC neurons of HFD mice (Schneeberger et al. 2013),

Published by Bioscientifica Ltd. 


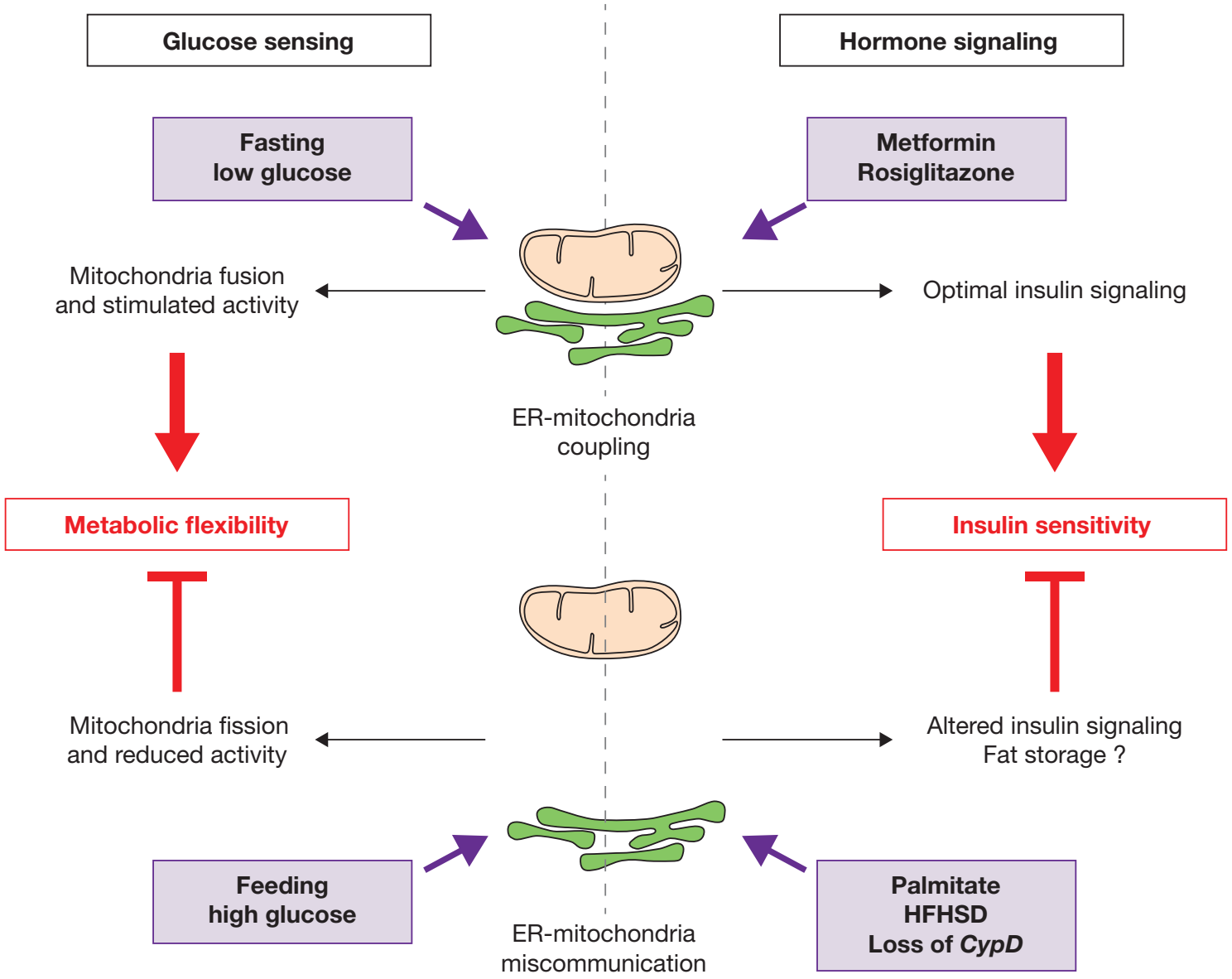

Figure 3

Role of ER-mitochondria miscommunication in metabolic diseases. At top: optimal ER-mitochondria interactions are required for metabolic flexibility (left) and insulin signaling (right). Top left: increased organelle interactions at fasting state promote mitochondria fusion and maximal oxidative capacities to predominantly oxidize lipids. Top right: antidiabetic drugs improve both insulin sensitivity and organelle interactions in diabetic mice. At the bottom: ER-mitochondria miscommunication is involved in metabolic inflexibility during nutritional transition (left) and in insulin resistance (right). Bottom left: high glucose levels reduce ER-mitochondria interactions at post-prandial state, presumably leading to the storage of excess of glucose into lipids. Bottom right: palmitate treatment, high-fat and high-sucrose diet (HFHSD) feeding or loss of cyclophilin D (CypD) reduces both organelle interactions and insulin sensitivity.

suggesting a miscommunication between ER and mitochondria in multiple tissues in the context of T2DM. A link between disrupted MAM and insulin resistance was also found in white adipose tissue of mice deficient in Cisd2 (also known as WFS2), an ironsulfur protein localized at MAM interface (Chen et al. 2009, Wang et al. 2014).

Recently, another group reported that MAM content is conversely increased in the liver of obese mice, leading to mitochondrial $\mathrm{Ca}^{2+}$ overload and mitochondrial dysfunction (Arruda et al. 2014). They further showed that reinforcing hepatic MAM by IP3R1 or PACS2 overexpression induced insulin resistance, whereas reducing the expression of these proteins in liver of obese mice improved insulin sensitivity (Arruda et al. 2014).
The discrepancy between studies is actually unclear but could be related to differences in mice metabolic status, environmental housing conditions or experimental analysis. Indeed, it is possible that MAMs are sensitive to a variety of environmental signals, from nutrients to pathogens. As both mitochondria (Hummasti \& Hotamisligil 2010) and ER (Chaudhari et al. 2014) have been recently involved in the modulation of immune responses, modifications of environmental conditions, such as changes in microbiota flora and activation of immune signals, could explain the discrepancy between results. Furthermore, as no MAM proteins are specific to this subcellular compartment, we cannot exclude that modulating their expression could have non-specific effects, further participating to the discrepancy between

Published by Bioscientifica Ltd 
studies. Along these lines, reduced or excessive ERmitochondria contacts, likely depending on the timing of the adaptive response upon a metabolic challenge, could represent a new and important mechanism contributing to hepatic mitochondrial dysfunction and insulin resistance. Future studies in which MAM will be dynamically studied are required to clarify this element.

\section{ER-mitochondria miscommunication and metabolic inflexibility}

Metabolic flexibility is the capacity of a cell to switch from lipid to glucose utilization during fasted-to-fed transition, and metabolic diseases are classically associated with metabolic inflexibility (Galgani et al. 2008). Importantly, we found that chronic disruption of MAM in the liver of insulin-resistant mice is associated with a loss of MAM regulation by energy state. Indeed, fasting-to-postprandial transition reduced ER-mitochondria interactions in liver of wt mice, whereas this regulation is lost in the liver of obese and diabetic mice (Theurey et al. 2016). Furthermore, sucrose consumption in drinking water also reduced ER-mitochondria interactions in liver of fasted wt mice, whereas this regulation is lost in the liver of $o b / o b$ and CypD-KO mice, both characterized by chronic disruption of MAM integrity, mitochondrial fission and altered mitochondrial respiration. As the regulation of ER-mitochondria interaction by glucose levels allows to control mitochondria dynamics and function and was also suggested to adapt hepatic metabolism to nutritional state, chronic disruption of MAM could participate to both hepatic metabolic inflexibility and mitochondrial dysfunction associated with hepatic insulin resistance. In line with this evidence, ER-mitochondria interactions are controlled by PP2A (Theurey et al. 2016), and hyperactivation of PP2A was associated with insulin resistance (Kowluru \& Matti 2012). Therefore, increased PP2A activity could participate in the disruption of MAM in the liver of insulin-resistant mice. Future studies are required to understand the molecular mechanisms of MAM disruption in the context of hepatic metabolic diseases and their role in metabolic inflexibility.

\section{ER-mitochondria miscommunication and other diseases associated with metabolic alterations}

Several human pathologies exhibiting alterations of both organelle and $\mathrm{Ca}^{2+}$ homeostasis are associated with metabolic perturbations. This is the case of neurodegenerative diseases, such as Alzheimer's disease
(AD) (Kandimalla et al. 2016), viral infections (Kralj et al. 2016), Wolfram syndrome (Boutzios et al. 2011) or some cancers (Klil-Drori et al. 2016). Interestingly, ERmitochondria miscommunication has recently been suggested or reported in these pathologies. However, it is still unclear whether MAM alterations in these pathologies contribute to the metabolic phenotype of patients.

In $\mathrm{AD}$, high levels of $\beta$-amyloid plaques are observed, which are generated by the proteolytic cleavage of amyloid precursor protein by presenilin- 1 and -2 , components of the $\gamma$-secretase complex (Area-Gomez \& Schon 2016). The molecular mechanism underlying the physiopathology of $\mathrm{AD}$ is rather unclear, but $\mathrm{AD}$ has interestingly been associated with altered metabolism, altered $\mathrm{Ca}^{2+}$ homeostasis and mitochondrial dysfunction. Consistent with these alterations, several evidence suggested that MAMs may play a role in neurodegenerative diseases, including $\mathrm{AD}$, as recently highlighted by several reviews (Volgyi et al. 2015, Area-Gomez \& Schon 2016, Joshi et al. 2016, Krols et al. 2016, Paillusson et al. 2016). Indeed, presenilins are enriched at MAM (Area-Gomez et al. 2009). Furthermore, ER-mitochondria interactions and MAM functionality (cholesteryl ester synthesis and PL transfer) are increased in fibroblasts from AD patients, in fibroblasts from mouse models of $\mathrm{AD}$, as well as in cell expressing gain-of-function mutation of presenilin (AreaGomez et al. 2012, Area-Gomez \& Schon 2016). However, whether ER-mitochondria hyperconnectivity participates to the AD-associated alterations of lipid, $\mathrm{Ca}^{2+}$ and mitochondria, as well as to the pathology itself, requires further investigations. Although it remains a challenge to clearly demonstrate the existence of a causal relationship between MAM and $\mathrm{AD}$, these preliminary data are rather exciting.

Concerning viral infections, several viral proteins were shown to localize to MAM (for reviews, see Williamson \& Colberg-Poley 2009, Colberg-Poley et al. 2015, de Armas-Rillo et al. 2016). This is the case for the human cytomegalovirus exon 1 protein and viral mitochondrialocalized inhibitor of apoptosis (Bozidis et al. 2010, Zhang et al. 2011, 2013), for the hepatitis C virus core protein (Williamson \& Colberg-Poley 2009, Horner et al. 2011, 2015), for the human immunodeficiency virus protein-R (Huang et al. 2012) and for the dengue virus (Chatel-Chaix et al. 2016). The localization of some viral proteins at MAM was reported either to induce changes in the abundance of cellular proteins at MAM (Bozidis et al. 2010, Zhang et al. 2011, 2013) or to disrupt ER-mitochondria interactions in host cells (Huang et al. 2012, Chatel-Chaix et al. 2016). Affecting MAM structure

Published by Bioscientifica Ltd. 
and function may enable viruses to reprogram cellular metabolism. Therefore, further studies deciphering how this subcellular domain might be manipulated are required to improve anticancer therapies.

Wolfram syndrome (WFS) is a rare neurodegenerative and metabolic disorder associated with a shortened lifespan. Mutations in human CISD2/WFS2, an iron-sulfur protein localized in the ER, cause WFS (Amr et al. 2007). Interestingly, CISD2 was localized at MAM (Wang et al. 2014), and adipocyte-specific loss of Cisd2 is associated with a reduction of ER-mitochondria interactions, mitochondrial dysfunction and altered insulin signaling in adipose tissue (Wang et al. 2014). Therefore, ERmitochondria miscommunication may play a role in metabolic alterations of WFS patients. Future studies are required to clarify this issue.

Recent evidences suggest a role of MAM in cancer disease, as this subcellular domain is a platform for several oncogenes and tumor suppressors (Marchi et al. 2014). The first link comes from studies on PML, a tumor suppressor frequently altered in cancers (Gurrieri et al. 2004). Interestingly, PML is present at the MAM interface where it controls both apoptosis (Giorgi et al. 2010) and autophagy (Missiroli et al. 2016). The proapoptotic and anti-autophagic action of PML relies on its role to transfer $\mathrm{Ca}^{2+}$ from ER to mitochondria, through the control of AKTmediated IP3R phosphorylation (Giorgi et al. 2010). Other tumor suppressors, such as PTEN (Bononi et al. 2013) and p53 (Giorgi et al. 2015a), have also been localized at the MAM interface and regulate $\mathrm{Ca}^{2+}$ flux and apoptosis by regulating AKT activity. Recently, two other tumorrelated proteins regulating $\mathrm{Ca}^{2+}$ transfer at MAM emerged as prognosis indicators in some cancers. For example, FATE1, a cancer-testis antigen localized at MAM, was recently implicated in the regulation of $\mathrm{Ca}^{2+}$ and drugdependent apoptosis in cancer cells by modulating ERmitochondria distance. Therefore, high FATE1 expression in the tumor is a poor prognosis indicator in patients with adrenocortical carcinoma (Doghman-Bouguerra et al. 2016). Furthermore, the ER-localized thioredoxin-related transmembrane protein 1 (TMX1) was shown to interact with SERCA2b under oxidizing conditions in a thioldependent manner to decrease SERCA activity and, thus, the ER $\mathrm{Ca}^{2+}$ load. Therefore, cancer cells with low TMX1 exhibit increased ER $\mathrm{Ca}^{2+}$, accelerated cytosolic $\mathrm{Ca}^{2+}$ clearance and reduced $\mathrm{Ca}^{2+}$ transfer to mitochondria, dampening mitochondria activity in tumor cells and favoring tumor growth (Raturi et al. 2016).

The interest of PP2A at ER-mitochondria contact sites could also have implications in these pathologies (Fig. 4).
Indeed, reduced PP2A activity has been observed in Alzheimer's disease (Sontag \& Sontag 2014) and in cancers (Grech et al. 2016), whereas an increased expression of the catalytic subunit of PP2A has been observed after viral infection (Tsunematsu et al. 2016). Until now, no link has been made between PP2A and WFS. In other words, the induction of ER-mitochondria interactions is associated with reduced PP2A activity in AD, whereas the reduction of ER-mitochondria interactions is associated with PP2A hyperactivation/hyperexpression in both T2DM and viral infection. In addition, the upregulation of PP2AC after $\mathrm{HCV}$ infection is involved in the alteration of insulinmediated glucose metabolism in liver (Tsunematsu et al. 2016), highlighting the importance of PP2A in the metabolic alterations induced by viral infection. Therefore, we suggest that the reciprocal regulation of both PP2A and MAM in these pathologies may point at an interesting relationship. Whether a different relocalization of PP2A at MAM interface participates to this antagonist regulation requires further studies. For cancers, it is still unknown whether ER-mitochondria interactions are modulated. However, the fact that PML is important for an appropriate $\mathrm{Ca}^{2+}$ flux in the MAM compartment by mediating the recruitment of PP2A (Giorgi et al. 2010), suggest a potential interplay between MAM, PP2A and cancers.

Even if all these observations are really preliminary, in the future, attention should be drawn to (i) the link between ER miscommunication and these pathologies, (ii) to the involvement of MAM in the metabolic alterations that occurs in these diseases, as well as (iii) to the role of PP2A at MAM interface.

\section{Looking for regulatory players of the ER-mitochondria crosstalk to treat metabolic diseases?}

As ER-mitochondria contact sites are dynamic and can change in size in response to nutritional and environmental cues, their targeting to improve metabolic diseases is an attractive perspective. However, the molecular mechanisms underlying how their crosstalk is regulated remains unclear. Recently, posttranslational modifications, such as palmitoylation, were shown to finely localize proteins at the MAM interface (Lynes et al. 2012). The emerging role of PP2A at MAM (Giorgi et al. 2010, Theurey et al. 2016) suggests that protein phosphorylation could be important for MAM functionality. In agreement, AKT and IP3R phosphorylation control inter-organelle $\mathrm{Ca}^{2+}$

Published by Bioscientifica Ltd. 


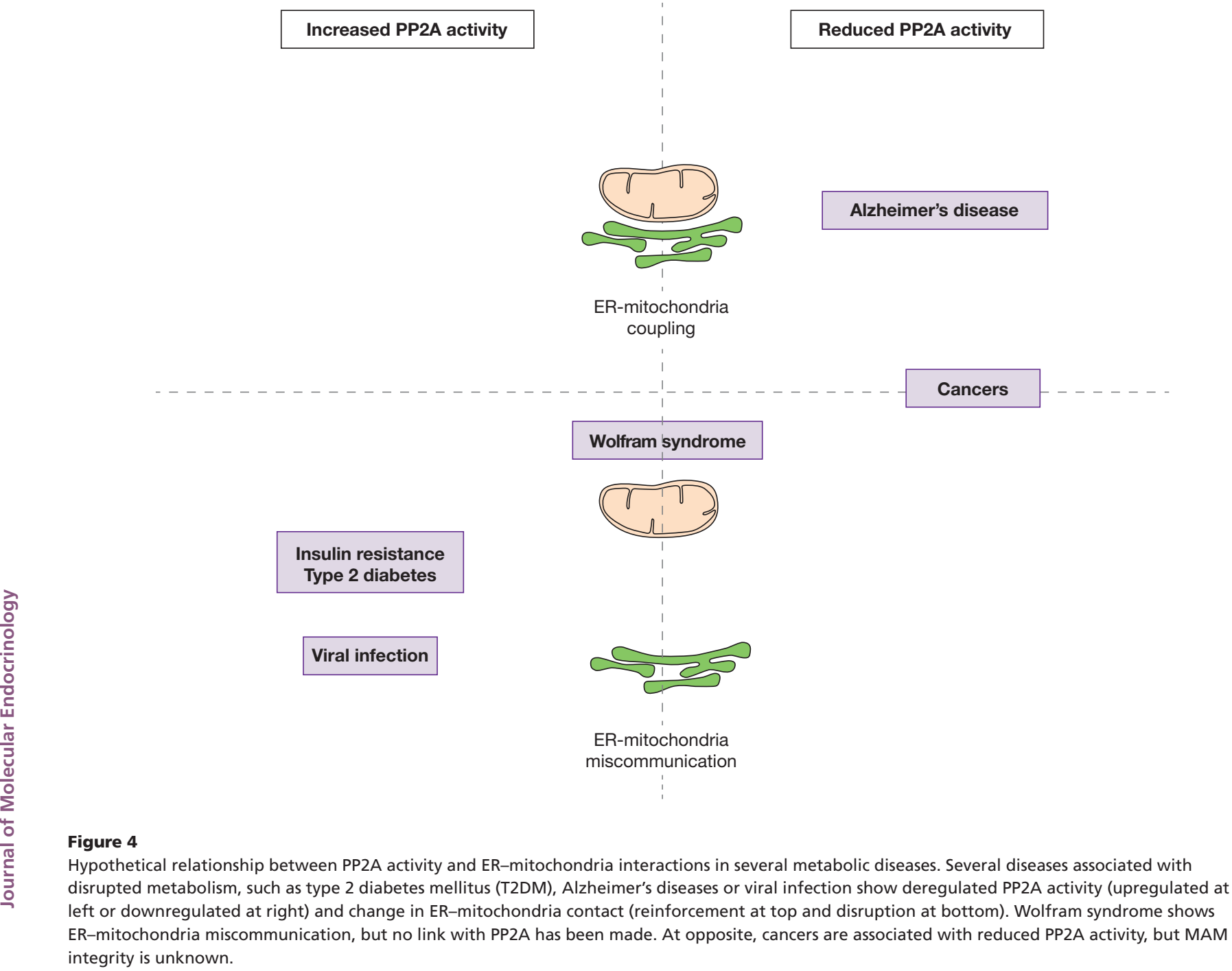

transfer efficiency (Khan et al. 2006, Marchi et al. 2008, Giorgi et al. 2010). Other proteins of MAM are also phosphorylated at this subdomain, such as mTORC2, PACS2 and hexokinase-2 (Betz et al. 2013). Further studies are necessary to clarify the role of posttranslational modifications in the regulation of MAM integrity and functionality.

\section{Conclusions}

Although the importance of ER-mitochondria communication in organelle homeostasis and cell fate is widely recognized, recent evidence indicates that MAM could also be an important hub for hormonal and nutrient signaling in hepatocytes, thus regulating metabolic homeostasis. Furthermore, recent studies highlight that ER-mitochondria miscommunication in the liver could contribute to metabolic diseases. However, these observations are clearly still in the initial stages to determine whether or not ER-mitochondria miscommunication contributes to metabolic diseases. Therefore, it will be important in the future to determine whether MAM integrity is required for hormone and nutrient signaling in other cell types as well as in hepatocytes. Furthermore, the results described in this review are rather correlative and future studies should determine whether ER-mitochondria miscommunication is a cause or a consequence of metabolic diseases. Finally, the relevance of this interesting relationship between MAM and metabolic homeostasis needs to be investigated in humans. Although care should be taken to ensure proper analysis of MAM components, functions and subsequent regulated signaling pathways, further dynamic studies are now required to clarify the nutritional regulation of http://jme.endocrinology-journals.org DOI: 10.1530/JME-16-0189
() 2017 Society for Endocrinology Printed in Great Britain
Published by Bioscientifica Ltd 
MAM, the role of MAM in cellular metabolism and the role of MAM disruption in the development of metabolic diseases. Strategies that specifically dampen or reinforce ER-mitochondria interactions in vivo, preferably in an inducible-manner, should help in the future to validate the role of MAM in metabolic diseases. Similarly, the molecular determinants of MAM, as well as the dynamic regulation of ER-mitochondria interactions, should be investigated to identify the key regulators of MAM integrity and functionality that could reveal themselves as pharmacological targets to modulate MAM and improve metabolic diseases. Whether PP2A could be a good target for the modulation of ER-mitochondria interactions and $\mathrm{Ca}^{2+}$ transfer requires further investigations. Nevertheless, it is unlikely that PP2A is the pharmacological target for improving metabolic diseases as this phosphatase has pleiotropic effects and its inhibition is pro-cancerous. Therefore, the next challenge is either to specifically target PP2A at MAM or to identify targets of PP2A at MAM, to specifically modulate ER-mitochondria crosstalk and potentially improve metabolic diseases. As PP2A is at the crossroad of several cellular signaling pathways and of several pathologies, there is no doubt that future studies will soon answer these fascinating questions.

\section{Declaration of interest}

The authors declare that there is no conflict of interest that could be perceived as prejudicing the impartiality of this review.

\section{Funding}

This work was funded by INSERM. E T was supported by a post-doc fellowship from Lund University.

\section{References}

Alam MR, Baetz D \& Ovize M 2015 Cyclophilin D and myocardial ischemia-reperfusion injury: a fresh perspective. Journal of Molecular and Cellular Cardiology 78 80-89. (doi:10.1016/j.yjmcc.2014.09.026)

Amr S, Heisey C, Zhang M, Xia XJ, Shows KH, Ajlouni K, Pandya A, Satin LS, El-Shanti H \& Shiang R 2007 A homozygous mutation in a novel zinc-finger protein, ERIS, is responsible for Wolfram syndrome 2. American Journal of Human Genetics 81 673-683. (doi:10.1086/520961)

Anelli T, Bergamelli L, Margittai E, Rimessi A, Fagioli C, Malgaroli A Pinton P, Ripamonti M, Rizzuto R \& Sitia R 2012 Ero1alpha regulates $\mathrm{Ca}(2+)$ fluxes at the endoplasmic reticulum-mitochondria interface (MAM). Antioxidants and Redox Signaling 16 1077-1087. (doi:10.1089/ ars.2011.4004)

Area-Gomez E \& Schon EA 2016 Mitochondria-associated ER membranes and Alzheimer disease. Current Opinion in Genetics and Development 38 90-96. (doi:10.1016/j.gde.2016.04.006)

Area-Gomez E, de Groof AJ, Boldogh I, Bird TD, Gibson GE, Koehler CM, Yu WH, Duff KE, Yaffe MP, Pon LA, et al. 2009 Presenilins are enriched in endoplasmic reticulum membranes associated with mitochondria. American Journal of Pathology 175 1810-1816. (doi:10.2353/ajpath.2009.090219)

Area-Gomez E, Del Carmen Lara Castillo M, Tambini MD, GuardiaLaguarta C, de Groof AJ, Madra M, Ikenouchi J, Umeda M, Bird TD, Sturley SL, et al. 2012 Upregulated function of mitochondriaassociated ER membranes in Alzheimer disease. EMBO Journal 31 4106-4123. (doi:10.1038/emboj.2012.202)

Arruda AP, Pers BM, Parlakgul G, Guney E, Inouye K \& Hotamisligil GS 2014 Chronic enrichment of hepatic endoplasmic reticulummitochondria contact leads to mitochondrial dysfunction in obesity. Nature Medicine 20 1427-1435. (doi:10.1038/nm.3735)

Ashraf NU \& Sheikh TA 2015 Endoplasmic reticulum stress and Oxidative stress in the pathogenesis of Non-alcoholic fatty liver disease. Free Radical Research 49 1405-1418. (doi:10.3109/10715762.2 015.1078461)

Aslan JE, You H, Williamson DM, Endig J, Youker RT, Thomas L, Shu H, Du Y, Milewski RL, Brush MH, et al. 2009 Akt and 14-3-3 control a PACS-2 homeostatic switch that integrates membrane traffic with TRAIL-induced apoptosis. Molecular Cell 34 497-509. (doi:10.1016/j. molcel.2009.04.011)

Begriche K, Massart J, Robin MA, Bonnet F \& Fromenty B 2013 Mitochondrial adaptations and dysfunctions in nonalcoholic fatty liver disease. Hepatology 58 1497-1507. (doi:10.1002/hep.26226)

Betz C, Stracka D, Prescianotto-Baschong C, Frieden M, Demaurex N \& Hall MN 2013 Feature Article: mTOR complex 2-Akt signaling at mitochondria-associated endoplasmic reticulum membranes (MAM) regulates mitochondrial physiology. PNAS 110 12526-12534. (doi:10.1073/pnas.1302455110)

Bononi A, Bonora M, Marchi S, Missiroli S, Poletti F, Giorgi C, Pandolfi PP \& Pinton P 2013 Identification of PTEN at the ER and MAMs and its regulation of Ca signaling and apoptosis in a protein phosphatase-dependent manner. Cell Death and Differentiation 20 1631-1643. (doi:10.1038/cdd.2013.77)

Bozidis P, Williamson CD, Wong DS \& Colberg-Poley AM 2010 Trafficking of UL37 proteins into mitochondrion-associated membranes during permissive human cytomegalovirus infection. Journal of Virology 84 7898-7903. (doi:10.1128/JVI.00885-10)

Boutzios G, Livadas S, Marinakis E, Opie N, Economou F \& Diamanti-Kandarakis E 2011 Endocrine and metabolic aspects of the Wolfram syndrome. Endocrine 40 10-13. (doi:10.1007/s12020011-9505-y)

Bravo R, Vicencio JM, Parra V, Troncoso R, Munoz JP, Bui M, Quiroga C, Rodriguez AE, Verdejo HE, Ferreira J, et al. 2011 Increased ERmitochondrial coupling promotes mitochondrial respiration and bioenergetics during early phases of ER stress. Journal of Cell Science 124 2143-2152. (doi:10.1242/jcs.080762)

Cardenas C, Miller RA, Smith I, Bui T, Molgo J, Muller M, Vais H, Cheung KH, Yang J, Parker I, et al. 2010 Essential regulation of cell bioenergetics by constitutive InsP3 receptor $\mathrm{Ca} 2+$ transfer to mitochondria. Cell 142 270-283. (doi:10.1016/j.cell.2010.06.007)

Chang YC, Hee SW, Hsieh ML, Jeng YM \& Chuang LM 2015 The role of organelle stresses in diabetes mellitus and obesity: implication for treatment. Analytical Cellular Pathology 2015972891. (doi:10.1155/2015/972891)

Chassaing B, Etienne-Mesmin L \& Gewirtz AT 2014 Microbiota-liver axis in hepatic disease. Hepatology 59 328-339. (doi:10.1002/hep.26494)

Chatel-Chaix L, Cortese M, Romero-Brey I, Bender S, Neufeldt CJ, Fischl W, Scaturro P, Schieber N, Schwab Y, Fischer B, et al. 2016 Dengue virus perturbs mitochondrial morphodynamics to dampen innate immune responses. Cell Host and Microbe 20 342-356. (doi:10.1016/j. chom.2016.07.008)

Chaudhari N, Talwar P, Parimisetty A, Lefebvre d'Hellencourt C \& Ravanan P 2014 A molecular web: endoplasmic reticulum stress, inflammation, and oxidative stress. Frontiers in Cellular Neuroscience 8 213. (doi:10.3389/fncel.2014.00213)

Published by Bioscientifica Ltd. 
Chen YF, Kao CH, Chen YT, Wang CH, Wu CY, Tsai CY, Liu FC, Yang CW, Wei YH, Hsu MT, et al. 2009 Cisd2 deficiency drives premature aging and causes mitochondria-mediated defects in mice. Genes and Development 23 1183-1194. (doi:10.1101/gad.1779509)

Colberg-Poley AM, Patterson GH, Salka K, Bhuvanendran S, Yang D \& Jaiswal JK 2015 Superresolution imaging of viral protein trafficking. Medical Microbiology and Immunology 204 449-460. (doi:10.1007/ s00430-015-0395-0)

Copeland DE \& Dalton, A. J. 1959 An association between mitochondria and the endoplasmic reticulum in cells of the pseudobranch gland of a teleost. Journal of Biophysical and Biochemical Cytology 5 393-396. (doi:10.1083/jcb.5.3.393)

Cosson P, Marchetti A, Ravazzola M \& Orci L 2012 Mitofusin-2 independent juxtaposition of endoplasmic reticulum and mitochondria: an ultrastructural study. PLOS ONE 7 e46293. (doi:10.1371/journal.pone.0046293)

Csordas G, Renken C, Varnai P, Walter L, Weaver D, Buttle KF, Balla T, Mannella CA \& Hajnoczky G 2006 Structural and functional features and significance of the physical linkage between ER and mitochondria. Journal of Cell Biology 174 915-921. (doi:10.1083/ jcb.200604016)

Csordas G, Varnai P, Golenar T, Roy S, Purkins G, Schneider TG, Balla T \& Hajnoczky G 2010 Imaging interorganelle contacts and local calcium dynamics at the ER-mitochondrial interface. Molecular Cell 39 121-132. (doi:10.1016/j.molcel.2010.06.029)

de Armas-Rillo L, Valera MS, Marrero-Hernandez S \& ValenzuelaFernandez A 2016 Membrane dynamics associated with viral infection. Reviews in Medical Virology 26 146-160. (doi:10.1002/ rmv.1872)

de Brito OM \& Scorrano L 2008 Mitofusin 2 tethers endoplasmic reticulum to mitochondria. Nature 456 605-610. (doi:10.1038/ nature07534)

Delzenne NM, Cani PD, Everard A, Neyrinck AM \& Bindels LB 2015 Gut microorganisms as promising targets for the management of type 2 diabetes. Diabetologia 58 2206-2217. (doi:10.1007/s00125015-3712-7)

Denton RM 2009 Regulation of mitochondrial dehydrogenases by calcium ions. Biochimica et Biophysica Acta 1787 1309-1316. (doi:10.1016/j.bbabio.2009.01.005)

Doghman-Bouguerra M, Granatiero V, Sbiera S, Sbiera I, Lacas-Gervais S, Brau F, Fassnacht M, Rizzuto R \& Lalli E 2016 FATE1 antagonizes calcium- and drug-induced apoptosis by uncoupling ER and mitochondria. EMBO Reports 17 1264-1280. (doi:10.15252/ embr.201541504)

Eriksson O, Fontaine E \& Bernardi P 1998 Chemical modification of arginines by 2,3-butanedione and phenylglyoxal causes closure of the mitochondrial permeability transition pore. Journal of Biological Chemistry 273 12669-12674. (doi:10.1074/jbc.273.20.12669)

Filadi R, Greotti E, Turacchio G, Luini A, Pozzan T \& Pizzo P 2015 Mitofusin 2 ablation increases endoplasmic reticulum-mitochondria coupling. PNAS 112 E2174-E2181. (doi:10.1073/pnas.1504880112)

Frank S, Gaume B, Bergmann-Leitner ES, Leitner WW, Robert EG, Catez F, Smith CL \& Youle RJ 2001 The role of dynamin-related protein 1, a mediator of mitochondrial fission, in apoptosis. Developmental Cell 1 515-525. (doi:10.1016/S1534-5807(01)00055-7)

Friedman JR, Lackner LL, West M, DiBenedetto JR, Nunnari J \& Voeltz GK 2011 ER tubules mark sites of mitochondrial division. Science 334 358-362. (doi:10.1126/science.1207385)

Galgani JE, Moro C \& Ravussin E 2008 Metabolic flexibility and insulin resistance. American Journal of Physiology: Endocrinology and Metabolism 295 E1009-E1017. (doi:10.1152/ajpendo.90558.2008)

Gan KX, Wang C, Chen JH, Zhu CJ \& Song GY 2013 Mitofusin-2 ameliorates high-fat diet-induced insulin resistance in liver of rats. World Journal of Gastroenterology 19 1572-1581. (doi:10.3748/wjg. v19.i10.1572)
Gao AW, Canto C \& Houtkooper RH 2014 Mitochondrial response to nutrient availability and its role in metabolic disease. EMBO Molecular Medicine 6 580-589. (doi:10.1002/emmm.201202150)

Giacomello M \& Pellegrini L 2016 The coming of age of the mitochondria-ER contact: a matter of thickness. Cell Death and Differentiation 23 1417-1427. (doi:10.1038/cdd.2016.52)

Gilady SY, Bui M, Lynes EM, Benson MD, Watts R, Vance JE \& Simmen T 2010 Ero1alpha requires oxidizing and normoxic conditions to localize to the mitochondria-associated membrane (MAM). Cell Stress and Chaperones 15 619-629. (doi:10.1007/s12192-010-0174-1)

Giorgi C, Ito K, Lin HK, Santangelo C, Wieckowski MR, Lebiedzinska M, Bononi A, Bonora M, Duszynski J, Bernardi $\mathrm{R}$, et al. 2010 PML regulates apoptosis at endoplasmic reticulum by modulating calcium release. Science 330 1247-1251. (doi:10.1126/science.1189157)

Giorgi C, Bonora M, Sorrentino G, Missiroli S, Poletti F, Suski JM, Galindo Ramirez F, Rizzuto R, Di Virgilio F, Zito E, et al. 2015 a p53 at the endoplasmic reticulum regulates apoptosis in a $\mathrm{Ca} 2+-$ dependent manner. PNAS 112 1779-1784. (doi:10.1073/ pnas.1410723112)

Giorgi C, Missiroli S, Patergnani S, Duszynski J, Wieckowski MR \& Pinton P $2015 b$ Mitochondria-associated membranes: composition, molecular mechanisms, and physiopathological implications. Antioxidants and Redox Signaling 22 995-1019. (doi:10.1089/ ars.2014.6223)

Grech G, Baldacchino S, Saliba C, Grixti MP, Gauci R, Petroni V, Fenech AG \& Scerri C 2016 Deregulation of the protein phosphatase 2A, PP2A in cancer: complexity and therapeutic options. Tumor Biology 37 11691-11700. (doi:10.1007/s13277-016-5145-4)

Gurrieri C, Capodieci P, Bernardi R, Scaglioni PP, Nafa K, Rush LJ, Verbel DA, Cordon-Cardo C \& Pandolfi PP 2004 Loss of the tumor suppressor PML in human cancers of multiple histologic origins. Journal of the National Cancer Institute 96 269-279. (doi:10.1093/jnci/ djh043)

Gutierrez T, Parra V, Troncoso R, Pennanen C, Contreras-Ferrat A, Vasquez-Trincado C, Morales PE, Lopez-Crisosto C, Sotomayor-Flores C, Chiong M, et al. 2014 Alteration in mitochondrial $\mathrm{Ca}(2+)$ uptake disrupts insulin signaling in hypertrophic cardiomyocytes. Cell Communication and Signaling 12 68. (doi:10.1186/ preaccept-1950166084128344)

Hagiwara A, Cornu M, Cybulski N, Polak P, Betz C, Trapani F, Terracciano L, Heim MH, Ruegg MA \& Hall MN 2012 Hepatic mTORC2 activates glycolysis and lipogenesis through Akt, glucokinase, and SREBP1c. Cell Metabolism 15 725-738. (doi:10.1016/j.cmet.2012.03.015)

Hailey DW, Rambold AS, Satpute-Krishnan P, Mitra K, Sougrat R, Kim PK \& Lippincott-Schwartz J 2010 Mitochondria supply membranes for autophagosome biogenesis during starvation. Cell 141 656-667. (doi:10.1016/j.cell.2010.04.009)

Hajnoczky G, Robb-Gaspers LD, Seitz MB \& Thomas AP 1995 Decoding of cytosolic calcium oscillations in the mitochondria. Cell $\mathbf{8 2}$ 415-424. (doi:10.1016/0092-8674(95)90430-1)

Hamasaki M, Furuta N, Matsuda A, Nezu A, Yamamoto A, Fujita N, Oomori H, Noda T, Haraguchi T, Hiraoka Y, et al. 2013 Autophagosomes form at ER-mitochondria contact sites. Nature 495 389-393. (doi:10.1038/nature11910)

Hasnain SZ, Prins JB \& McGuckin MA 2016 Oxidative and endoplasmic reticulum stress in beta-cell dysfunction in diabetes. Journal of Molecular Endocrinology 56 R33-R54. (doi:10.1530/JME-15-0232)

Hatahet F \& Ruddock LW 2009 Protein disulfide isomerase: a critical evaluation of its function in disulfide bond formation. Antioxidants and Redox Signaling 11 2807-2850. (doi:10.1089/ars.2009.2466)

Hayashi T \& Su TP 2007 Sigma-1 receptor chaperones at the ER-mitochondrion interface regulate $\mathrm{Ca}(2+)$ signaling and cell survival. Cell 131 596-610. (doi:10.1016/j.cell.2007.08.036) http://jme.endocrinology-journals.org

DOI: 10.1530/JME-16-0189
๑ 2017 Society for Endocrinology Printed in Great Britain
Published by Bioscientifica Ltd 
Hoppins S \& Nunnari J 2012 Cell Biology. Mitochondrial dynamics and apoptosis - the ER connection. Science 337 1052-1054. (doi:10.1126/ science.1224709)

Horner SM, Liu HM, Park HS, Briley J \& Gale M Jr 2011 Mitochondrialassociated endoplasmic reticulum membranes (MAM) form innate immune synapses and are targeted by hepatitis C virus. PNAS 108 14590-14595. (doi:10.1073/pnas.1110133108)

Horner SM, Wilkins C, Badil S, Iskarpatyoti J \& Gale M Jr 2015 Proteomic analysis of mitochondrial-associated ER membranes (MAM) during RNA virus infection reveals dynamic changes in protein and organelle trafficking. PLOS ONE 10 e0117963. (doi:10.1371/journal.pone.0117963)

Huang CY, Chiang SF, Lin TY, Chiou SH \& Chow KC 2012 HIV-1 Vpr triggers mitochondrial destruction by impairing Mfn2-mediated ER-mitochondria interaction. PLOS ONE 7 e33657. (doi:10.1371/ journal.pone.0033657)

Hummasti S \& Hotamisligil GS 2010 Endoplasmic reticulum stress and inflammation in obesity and diabetes. Circulation Research $\mathbf{1 0 7}$ 579-591. (doi:10.1161/CIRCRESAHA.110.225698)

Ishikawa H, Ma Z \& Barber GN 2009 STING regulates intracellular DNA-mediated, type I interferon-dependent innate immunity. Nature 461 788-792. (doi:10.1038/nature08476)

Jayaraman T \& Marks AR 1997 T cells deficient in inositol 1,4,5-trisphosphate receptor are resistant to apoptosis. Molecular and Cellular Biology 17 3005-3012. (doi:10.1128/MCB.17.6.3005)

Joshi AU, Kornfeld OS \& Mochly-Rosen D 2016 The entangled ER-mitochondrial axis as a potential therapeutic strategy in neurodegeneration: A tangled duo unchained. Cell Calcium 60 218-234. (doi:10.1016/j.ceca.2016.04.010)

Kandimalla R, Thirumala V \& Reddy PH 2016 Is Alzheimer's disease a type 3 diabetes? A critical appraisal. Biochimica et Biophysica Acta [in press]. (doi:10.1016/j.bbadis.2016.08.018)

Kaur J \& Debnath J 2015 Autophagy at the crossroads of catabolism and anabolism. Nature Reviews Molecular Cell Biology 16 461-472. (doi:10.1038/nrm4024)

Khan MT, Wagner L 2nd, Yule DI, Bhanumathy C \& Joseph SK 2006 Akt kinase phosphorylation of inositol 1,4,5-trisphosphate receptors. Journal of Biological Chemistry 281 3731-3737. (doi:10.1074/jbc. M509262200)

Klil-Drori AJ, Azoulay L \& Pollak MN 2016 Cancer, obesity, diabetes, and antidiabetic drugs: is the fog clearing? Nature Reviews Clinical Oncology [in press]. (doi:10.1038/nrclinonc.2016.120)

Korobova F, Ramabhadran V \& Higgs HN 2013 An actin-dependent step in mitochondrial fission mediated by the ER-associated formin INF2. Science 339 464-467. (doi:10.1126/science.1228360)

Kottgen M, Benzing T, Simmen T, Tauber R, Buchholz B, Feliciangeli S, Huber TB, Schermer B, Kramer-Zucker A, Hopker K, et al. 2005 Trafficking of TRPP2 by PACS proteins represents a novel mechanism of ion channel regulation. EMBO Journal 24 705-716. (doi:10.1038/ sj.emboj.7600566)

Kowluru A \& Matti A 2012 Hyperactivation of protein phosphatase 2A in models of glucolipotoxicity and diabetes: potential mechanisms and functional consequences. Biochemical Pharmacology 84 591-597. (doi:10.1016/j.bcp.2012.05.003)

Kralj D, Virović Jukić L, Stojsavljević S, Duvnjak M, Smolić M \& Čurčić IB 2016 Hepatitis C Virus, Insulin Resistance, and Steatosis. Journal of Clinical and Translational Hepatology 4 66-75. (doi:10.14218/ JCTH.2015.00051)

Krols M, van Isterdael G, Asselbergh B, Kremer A, Lippens S, Timmerman V \& Janssens S 2016 Mitochondria-associated membranes as hubs for neurodegeneration. Acta Neuropathologica 131 505-523. (doi:10.1007/s00401-015-1528-7)

Lackey DE \& Olefsky JM 2016 Regulation of metabolism by the innate immune system. Nature Reviews Endocrinology 12 15-28. (doi:10.1038/nrendo.2015.189)
Lartigue L \& Faustin B 2013 Mitochondria: metabolic regulators of innate immune responses to pathogens and cell stress. International Journal of Biochemistry and Cell Biology 45 2052-2056. (doi:10.1016/j. biocel.2013.06.014)

Lavallard VJ \& Gual P 2014 Autophagy and non-alcoholic fatty liver disease. BioMed Research International 2014120179. (doi:10.1155/2014/120179)

Li G, Mongillo M, Chin KT, Harding H, Ron D, Marks AR \& Tabas I 2009 Role of ERO1-alpha-mediated stimulation of inositol 1,4,5-triphosphate receptor activity in endoplasmic reticulum stressinduced apoptosis. Journal of Cell Biology 186 783-792. (doi:10.1083/ jcb.200904060)

Lim JH, Lee HJ, Ho Jung M \& Song J 2009 Coupling mitochondrial dysfunction to endoplasmic reticulum stress response: a molecular mechanism leading to hepatic insulin resistance. Cellular Signalling 21 169-177. (doi:10.1016/j.cellsig.2008.10.004)

Lynes EM, Bui M, Yap MC, Benson MD, Schneider B, Ellgaard L, Berthiaume LG \& Simmen T 2012 Palmitoylated TMX and calnexin target to the mitochondria-associated membrane. EMBO Journal 31 457-470. (doi:10.1038/emboj.2011.384)

Mandl J, Meszaros T, Banhegyi G, Hunyady L \& Csala M 2009 Endoplasmic reticulum: nutrient sensor in physiology and pathology. Trends in Endocrinology and Metabolism 20 194-201. (doi:10.1016/j.tem.2009.01.003)

Marchi S, Rimessi A, Giorgi C, Baldini C, Ferroni L, Rizzuto R \& Pinton P 2008 Akt kinase reducing endoplasmic reticulum Ca2+ release protects cells from $\mathrm{Ca} 2+-$ dependent apoptotic stimuli. Biochemical and Biophysical Research Communications 375 501-505. (doi:10.1016/j.bbrc.2008.07.153)

Marchi S, Patergnani S \& Pinton P 2014 The endoplasmic reticulummitochondria connection: one touch, multiple functions. Biochimica et Biophysica Acta 1837 461-469. (doi:10.1016/j.bbabio.2013.10.015)

Martinon F 2012 The endoplasmic reticulum: a sensor of cellular stress that modulates immune responses. Microbes and Infection 14 1293-1300. (doi:10.1016/j.micinf.2012.07.005)

Martins-Marques T, Ribeiro-Rodrigues T, Pereira P, Codogno P \& Girao H 2015 Autophagy and ubiquitination in cardiovascular diseases. DNA and Cell Biology 34 243-251. (doi:10.1089/dna.2014.2765)

Missiroli S, Bonora M, Patergnani S, Poletti F, Perrone M, Gafa R, Magri E, Raimondi A, Lanza G, Tacchetti C, et al. 2016 PML at mitochondria-associated membranes is critical for the repression of autophagy and cancer development. Cell Reports 16 2415-2427. (doi:10.1016/j.celrep.2016.07.082)

Montisano DF, Cascarano J, Pickett CB \& James TW 1982 Association between mitochondria and rough endoplasmic reticulum in rat liver. Anatomical Record 203 441-450. (doi:10.1002/ar.1092030403)

Mori T, Hayashi T, Hayashi E \& Su TP 2013 Sigma-1 receptor chaperone at the ER-mitochondrion interface mediates the mitochondrion-ERnucleus signaling for cellular survival. PLOS ONE 8 e76941. (doi:10.1371/journal.pone.0076941)

Munoz JP, Ivanova S, Sanchez-Wandelmer J, Martinez-Cristobal P, Noguera E, Sancho A, Diaz-Ramos A, Hernandez-Alvarez MI, Sebastian D, Mauvezin C, et al. 2013 Mfn2 modulates the UPR and mitochondrial function via repression of PERK. EMBO Journal 32 2348-2361. (doi:10.1038/emboj.2013.168)

Naon D \& Scorrano L 2014 At the right distance: ER-mitochondria juxtaposition in cell life and death. Biochimica et Biophysica Acta 1843 2184-2194. (doi:10.1016/j.bbamcr.2014.05.011)

Naon D, Zaninello M, Giacomello M, Varanita T, Grespi F, Lakshminaranayan S, Serafini A, Semenzato M, Herkenne S, Hernández-Alvarez MI, et al. 2016 Critical reappraisal confirms that Mitofusin 2 is an endoplasmic reticulum-mitochondria tether. PNAS 113 11249-11254. (doi:10.1073/pnas.1606786113)

Paillard M, Tubbs E, Thiebaut PA, Gomez L, Fauconnier J, Da Silva CC, Teixeira G, Mewton N, Belaidi E, Durand A, et al. 2013 Depressing http://jme.endocrinology-journals.org

DOI: 10.1530/JME-16-0189
() 2017 Society for Endocrinology Printed in Great Britain
Published by Bioscientifica Ltd 
mitochondria-reticulum interactions protects cardiomyocytes from lethal hypoxia-reoxygenation injury. Circulation 128 1555-1565. (doi:10.1161/CIRCULATIONAHA.113.001225)

Paillusson S, Stoica R, Gomez-Suaga P, Lau DH, Mueller S, Miller T \& Miller CC 2016 There's something wrong with my MAM; the ER-mitochondria axis and neurodegenerative diseases. Trends in Neurosciences 39 146-157. (doi:10.1016/j.tins.2016.01.008)

Poston CN, Duong E, Cao Y \& Bazemore-Walker CR 2011 Proteomic analysis of lipid raft-enriched membranes isolated from internal organelles. Biochemical and Biophysical Research Communications 415 355-360. (doi:10.1016/j.bbrc.2011.10.072)

Raturi A, Gutiérrez T, Ortiz-Sandoval C, Ruangkittisakul A, Herrera-Cruz MS, Rockley JP, Gesson K, Ourdev D, Lou PH, Lucchinetti E, et al. 2016 TMX1 determines cancer cell metabolism as a thiol-based modulator of ER-mitochondria Ca2+ flux. Journal of Cell Biology 214 433-444. (doi:10.1083/jcb.201512077)

Rieusset J 2015 Contribution of mitochondria and endoplasmic reticulum dysfunction in insulin resistance: distinct or interrelated roles? Diabetes and Metabolism 41 358-368. (doi:10.1016/j. diabet.2015.02.006)

Rieusset J, Fauconnier J, Paillard M, Belaidi E, Tubbs E, Chauvin MA, Durand A, Bravard A, Teixeira G, Bartosch B, et al. 2016 Disruption of calcium transfer from ER to mitochondria links alterations of mitochondria-associated ER membrane integrity to hepatic insulin resistance. Diabetologia 59 614-623. (doi:10.1007/s00125-015-3829-8)

Rizzuto R \& Pozzan T 2006 Microdomains of intracellular Ca2+: molecular determinants and functional consequences. Physiological Reviews 86 369-408. (doi:10.1152/physrev.00004.2005)

Rizzuto R, Brini M \& Pozzan T 1993 Intracellular targeting of the photoprotein aequorin: a new approach for measuring, in living cells, $\mathrm{Ca} 2+$ concentrations in defined cellular compartments. Cytotechnology 11 (Supplement 1) S44-S46. (doi:10.1007/ BF00746051)

Rizzuto R, Pinton P, Carrington W, Fay FS, Fogarty KE, Lifshitz LM, Tuft RA \& Pozzan T 1998 Close contacts with the endoplasmic reticulum as determinants of mitochondrial $\mathrm{Ca} 2+$ responses. Science $\mathbf{2 8 0}$ 1763-1766. (doi:10.1126/science.280.5370.1763)

Rizzuto R, De Stefani D, Raffaello A \& Mammucari C 2012 Mitochondria as sensors and regulators of calcium signalling. Nature Reviews Molecular Cell Biology 13 566-578. (doi:10.1038/nrm3412)

Rowland AA \& Voeltz GK 2012 Endoplasmic reticulum-mitochondria contacts: function of the junction. Nature Reviews Molecular Cell Biology 13 607-625. (doi:10.1038/nrm3440)

Sala-Vila A, Navarro-Lérida I, Sánchez-Alvarez M, Bosch M, Calvo C, López JA, Calvo E, Ferguson C, Giacomello M, Serafini A, et al. 2016 Interplay between hepatic mitochondria-associated membranes, lipid metabolism and caveolin-1 in mice. Scientific Reports 627351. (doi:10.1038/srep27351)

Salvado L, Palomer X, Barroso E \& Vazquez-Carrera M 2015 Targeting endoplasmic reticulum stress in insulin resistance. Trends in Endocrinology and Metabolism 26 438-448. (doi:10.1016/j. tem.2015.05.007)

Schneeberger M, Dietrich MO, Sebastian D, Imbernon M, Castano C, Garcia A, Esteban Y, Gonzalez-Franquesa A, Rodriguez IC, Bortolozzi A, et al. 2013 Mitofusin 2 in POMC neurons connects ER stress with leptin resistance and energy imbalance. Cell 155 172-187. (doi:10.1016/j.cell.2013.09.003)

Schroder M 2008 Endoplasmic reticulum stress responses. Cellular and Molecular Life Sciences 65 862-894. (doi:10.1007/s00018-007-7383-5)

Scorrano L, Oakes SA, Opferman JT, Cheng EH, Sorcinelli MD, Pozzan T \& Korsmeyer SJ 2003 BAX and BAK regulation of endoplasmic reticulum Ca2+: a control point for apoptosis. Science 300 135-139. (doi:10.1126/science.1081208)

Sebastian D, Hernandez-Alvarez MI, Segales J, Sorianello E, Munoz JP, Sala D, Waget A, Liesa M, Paz JC, Gopalacharyulu P, et al. 2012 Mitofusin 2 (Mfn2) links mitochondrial and endoplasmic reticulum function with insulin signaling and is essential for normal glucose homeostasis. PNAS 109 5523-5528. (doi:10.1073/ pnas.1108220109)

Simmen T, Aslan JE, Blagoveshchenskaya AD, Thomas L, Wan L, Xiang Y, Feliciangeli SF, Hung CH, Crump CM \& Thomas G 2005 PACS-2 controls endoplasmic reticulum-mitochondria communication and Bid-mediated apoptosis. EMBO Journal 24 717-729. (doi:10.1038/ sj.emboj.7600559)

Simmen T, Lynes EM, Gesson K \& Thomas G 2010 Oxidative protein folding in the endoplasmic reticulum: tight links to the mitochondria-associated membrane (MAM). Biochimica et Biophysica Acta 1798 1465-1473. (doi:10.1016/j.bbamem.2010.04.009)

Soltys SM, Kashani JH, Dandoy AC, Vaidya AF \& Reid JC 1992 Comorbidity for disruptive behavior disorders in psychiatrically hospitalized children. Child Psychiatry and Human Development 23 87-98. (doi:10.1007/BF00709752)

Sontag JM \& Sontag E 2014 Protein phosphatase 2A dysfunction in Alzheimer's disease. Frontiers in Molecular Neuroscience $\mathbf{7} 16$. (doi:10.3389/fnmol.2014.00016)

Sood A, Jeyaraju DV, Prudent J, Caron A, Lemieux P, McBride HM, Laplante M, Toth K \& Pellegrini L 2014 A Mitofusin-2-dependent inactivating cleavage of Opa1 links changes in mitochondria cristae and ER contacts in the post-prandial liver. PNAS 111 16017-16022. (doi:10.1073/pnas.1408061111)

Sugiura A, Nagashima S, Tokuyama T, Amo T, Matsuki Y, Ishido S, Kudo Y, McBride HM, Fukuda T, Matsushita N, et al. 2013 MITOL regulates endoplasmic reticulum-mitochondria contacts via Mitofusin2. Molecular Cell 51 20-34. (doi:10.1016/j. molcel.2013.04.023)

Szabadkai G, Bianchi K, Varnai P, De Stefani D, Wieckowski MR, Cavagna D, Nagy AI, Balla T \& Rizzuto R 2006 Chaperone-mediated coupling of endoplasmic reticulum and mitochondrial Ca2+ channels. Journal of Cell Biology 175 901-911. (doi:10.1083/ jcb.200608073)

Szado T, Vanderheyden V, Parys JB, De Smedt H, Rietdorf K, Kotelevets L, Chastre E, Khan F, Landegren U, Soderberg O, et al. 2008 Phosphorylation of inositol 1,4,5-trisphosphate receptors by protein kinase B/Akt inhibits Ca2+ release and apoptosis. PNAS 105 2427-2432. (doi:10.1073/pnas.0711324105)

Takaki A, Kawai D \& Yamamoto K 2014 Molecular mechanisms and new treatment strategies for non-alcoholic steatohepatitis (NASH). International Journal of Molecular Sciences 15 7352-7379. (doi:10.3390/ ijms15057352)

Theurey P, Tubbs E, Vial G, Jacquemetton J, Bendridi N, Chauvin MA, Alam MR, Le Romancer M, Vidal H \& Rieusset J 2016 Mitochondriaassociated endoplasmic reticulum membranes allow adaptation of mitochondrial metabolism to glucose availability in the liver. Journal of Molecular Cell Biology 8 129-143. (doi:10.1093/jmcb/mjw004)

Tschopp J 2011 Mitochondria: sovereign of inflammation? European Journal of Immunology 41 1196-1202. (doi:10.1002/eji.201141436)

Tsunematsu S, Suda G, Yamasaki K, Kimura M, Izumi T, Umemura M, Ito J, Sato F, Nakai M, Sho T, et al. 2016 Hepatitis B virus X protein impairs alpha-interferon signaling via up-regulation of suppressor of cytokine signaling 3 and protein phosphatase 2A. Journal of Medical Virology 89 267-275. (doi:10.1002/jmv.24643)

Tubbs E, Theurey P, Vial G, Bendridi N, Bravard A, Chauvin MA, Ji-Cao J, Zoulim F, Bartosch B, Ovize M, et al. 2014 Mitochondria-associated endoplasmic reticulum membrane (MAM) integrity is required for insulin signaling and is implicated in hepatic insulin resistance. Diabetes 63 3279-3294. (doi:10.2337/db13-1751)

van Vliet AR, Verfaillie T \& Agostinis P 2014 New functions of mitochondria associated membranes in cellular signaling. Biochimica et Biophysica Acta 1843 2253-2262. (doi:10.1016/j. bbamcr.2014.03.009)

Vance JE 1990 Phospholipid synthesis in a membrane fraction associated with mitochondria. Journal of Biological Chemistry 265 7248-7256.

Published by Bioscientifica Ltd 
Vance JE 2014 MAM (mitochondria-associated membranes) in mammalian cells: lipids and beyond. Biochimica et Biophysica Acta 1841 595-609. (doi:10.1016/j.bbalip.2013.11.014)

Verfaillie T, Rubio N, Garg AD, Bultynck G, Rizzuto R, Decuypere JP, Piette J, Linehan C, Gupta S, Samali A, et al. 2012 PERK is required at the ER-mitochondrial contact sites to convey apoptosis after ROSbased ER stress. Cell Death and Differentiation 19 1880-1891. (doi:10.1038/cdd.2012.74)

Volgyi K, Juhász G, Kovacs Z \& Penke B 2015 Dysfunction of endoplasmic reticulum (ER) and mitochondria (MT) in Alzheimer's disease: the role of the ER-MT cross-talk. Current Alzheimer Research 12 655-672. (doi:10.2174/1567205012666150710095035)

Wang J \& Pantopoulos K 2011 Regulation of cellular iron metabolism. Biochemical Journal 434 365-381. (doi:10.1042/BJ20101825)

Wang $\mathrm{CH}$, Chen YF, Wu CY, Wu PC, Huang YL, Kao CH, Lin CH, Kao LS, Tsai TF \& Wei YH 2014 Cisd2 modulates the differentiation and functioning of adipocytes by regulating intracellular $\mathrm{Ca} 2+$ homeostasis. Human Molecular Genetics 23 4770-4785. (doi:10.1093/ hmg/ddu193)

Wang CH, Tsai TF \& Wei YH 2015 Role of mitochondrial dysfunction and dysregulation of $\mathrm{Ca}(2+)$ homeostasis in insulin insensitivity of mammalian cells. Annals of the New York Academy of Sciences 1350 66-76. (doi:10.1111/nyas.12838)

Williamson CD \& Colberg-Poley AM 2009 Access of viral proteins to mitochondria via mitochondria-associated membranes. Reviews in Medical Virology 19 147-164. (doi:10.1002/rmv.611)
Wong PM, Feng Y, Wang J, Shi R \& Jiang X 2015 Regulation of autophagy by coordinated action of mTORC1 and protein phosphatase 2A. Nature Communications 6 8048. (doi:10.1038/ ncomms9048)

Yang J 2010 Role of clusters in insulin-regulated GLUT4 trafficking in adipose cells: a new paradigm? International Journal of Biological Sciences 6 716-718. (doi:10.7150/ijbs.6.716)

Zhang H, Liu Q, Zimmerman LJ, Ham AJ, Slebos RJ, Rahman J, Kikuchi T, Massion PP, Carbone DP, Billheimer D, et al. 2011 Methods for peptide and protein quantitation by liquid chromatography-multiple reaction monitoring mass spectrometry. Molecular Cell Proteomics 10 M110 006593. (doi:10.1074/mcp. M110.006593)

Zhang J, Xin L, Shan B, Chen W, Xie M, Yuen D, Zhang W, Zhang Z, Lajoie GA \& Ma B 2012 PEAKS DB: de novo sequencing assisted database search for sensitive and accurate peptide identification. Molecular Cell Proteomics 11 M111 010587. (doi:10.1074/mcp. m111.010587)

Zhang Y, Zhao Z, Sun J, Cao G, Zhao F, Hu J, Liu L \& Ji Y 2013 A new mutation in the human cytomegalovirus UL97 gene may confer ganciclovir resistance in Chinese kidney transplant recipients. Archives of Virology 158 247-250. (doi:10.1007/s00705012-1479-4)

Zhou R, Yazdi AS, Menu P \& Tschopp J 2011 A role for mitochondria in NLRP3 inflammasome activation. Nature 469 221-225. (doi:10.1038/ nature09663)

Received in final form 7 December 2016

Accepted 13 December 2016

Accepted Preprint published online 13 December 2016 http://jme.endocrinology-journals.org DOI: 10.1530/JME-16-0189
() 2017 Society for Endocrinology Printed in Great Britain
Published by Bioscientifica Ltd 